\title{
Deep time diversity of metatherian mammals: implications for evolutionary history and fossil-record quality
}

\author{
C. Verity Bennett, Paul Upchurch, Francisco J. Goin, and Anjali Goswami
}

\begin{abstract}
Despite a global fossil record, Metatheria are now largely restricted to Australasia and South America. Most metatherian paleodiversity studies to date are limited to particular subclades, time intervals, and/or regions, and few consider uneven sampling. Here, we present a comprehensive new data set on metatherian fossil occurrences (Barremian to end Pliocene). These data are analyzed using standard rarefaction and shareholder quorum subsampling (including a new protocol for handling Lagerstätte-like localities).

Global metatherian diversity was lowest during the Cretaceous, and increased sharply in the Paleocene, when the South American record begins. Global and South American diversity rose in the early Eocene then fell in the late Eocene, in contrast to the North American pattern. In the Oligocene, diversity declined in the Americas, but this was more than offset by Oligocene radiations in Australia. Diversity continued to decrease in Laurasia, with final representatives in North America (excluding the later entry of Didelphis virginiana) and Europe in the early Miocene, and Asia in the middle Miocene. Global metatherian diversity appears to have peaked in the early Miocene, especially in Australia. Following a trough in the late Miocene, the Pliocene saw another increase in global diversity. By this time, metatherian biogeographic distribution had essentially contracted to that of today.

Comparison of the raw and sampling-corrected diversity estimates, coupled with evaluation of "coverage" and number of prolific sites, demonstrates that the metatherian fossil record is spatially and temporally extremely patchy. Therefore, assessments of macroevolutionary patterns based on the raw fossil record (as in most previous studies) are inadvisable.
\end{abstract}

C. Verity Bennett. Department of Genetics, Evolution and Environment, University College London, Gower Street, London WC1E 6BT, United Kingdom. E-mail: bennettcv@cf.ac.uk. Present address: Division of Population Medicine, Cardiff University, Heath Park, Cardiff CF14 4YS, United Kingdom.

Paul Upchurch. Department of Earth Sciences, University College London, Gower Street, London WC1E 6BT, United Kingdom. E-mail: p.upchurch@ucl.ac.uk

Francisco J. Goin. CONICET-División Paleontología Vertebrados, Museo de La Plata, La Plata, Argentina. E-mail: fgoin@fcnym.unlp.edu.ar

Anjali Goswami. Department of Genetics, Evolution and Environment and Department of Earth Sciences,

University College London, Gower Street, London WC1E 6BT, United Kingdom. E-mail: a.goswami@nhm.ac.uk.

Present address: Department of Life Sciences, The Natural History Museum, Cromwell Road, London SW7 5BD.

Accepted: 16 October 2017

Published online: 6 February 2018

Data available from the Dryad Digital Repository: http:/ /dx.doi.org/10.5061/dryad.bt651

\section{Introduction}

Therian mammals comprise the Metatheria and Eutheria, represented today by the crown clades marsupials and placentals, respectively, and belong to the boreosphenidan clade of tribosphenic mammals that is thought to have originated on the northern landmass of Laurasia (Luo et al. 2001; Williamson et al. 2014). However, despite their shared evolutionary history, marsupials and placentals have disparate modern diversities. Extant placentals comprise more than 5000 species in
20 orders and are a globally distributed group, whereas extant marsupials comprise approximately 330 species belonging to 7 orders (Reeder et al. 2007). Extant marsupials are also more limited in ecomorphological diversity (Sears 2004; Bennett and Goswami 2013) and in geographical distribution (Lillegraven 1974), which is today limited to three continents. Despite dominating the Australian mammalian fauna, marsupials are found additionally only in South and Central America (approximately 90 species) and have one species, Didelphis virginiana, in North America (Wilson and Reeder 2005;

(C) 2018 The Paleontological Society. All rights reserved. This is an Open Access article, distributed under the terms of the Creative Commons Attribution licence (http://creativecommons.org/licenses/by/4.0/), which permits unrestricted reuse, distribution, and reproduction in any medium, provided the original work is properly cited. 
Reeder et al. 2007), which only invaded the continent in the last 1 Myr (Woodburne 2010).

In contrast to metatherians' present-day distribution, their fossil record is globally distributed. The earliest metatherian, Sinodelphys szalayi (Luo et al. 2003), is known from the Early Cretaceous Yixian Formation of China. Other Early Cretaceous metatherians have been found elsewhere in Asia and in Europe, but their greatest Cretaceous diversity occurs in North America, where they outnumbered eutherians prior to the Cretaceous/ Paleogene (hereafter, K/Pg) mass extinction (Cifelli and Davis 2003; Williamson et al. 2014). The ecological diversity of extinct metatherians has also been proposed to be higher than present, with enigmatic forms such as Thylacosmilus (Riggs 1934), a sabertoothed marsupial from the Pliocene of South America; Diprotodon (Owen 1838), a hippopotamus-sized Australian herbivore; and the "marsupial woodpecker" Yalkaparidon (Archer et al. 1988; Beck 2009).

Multiple factors have been proposed as the drivers of the marked differences in the extant biodiversity of the two therian sister clades. In particular, the consequences of the marsupial reproductive strategy and current geographic distribution have been discussed at length (Lillegraven 1974, 1975; Sears 2004; SánchezVillagra 2013; Bennett and Goswami 2013; Goswami et al. 2016), although the latter in particular has not been robustly tested. The low taxonomic and morphological diversity of Metatheria have been attributed to developmental constraints stemming from their short gestation period and subsequent crawl to the pouch and lengthy period of suckling. These requirements have been implicated in restricting novel morphologies, because of the need for early-functioning mouthparts and forelimbs (Lillegraven 1975; Sears 2004; Kelly and Sears 2011; Bennett and Goswami 2013; Goswami et al. 2016). Additionally, physiological hypotheses such as lower energy efficiency of the marsupial reproductive mode, which has been suggested to limit their reproductive rate compared with placentals (Lillegraven 1975; Morton et al. 1982), and lower basal metabolic rate (BMR) in marsupials versus placentals (Goin et al. 2016, and references there in) have also been suggested to play a role in constraining diversity. Conversely, Sánchez-Villagra (2013) postulated that the restriction of marsupials to the southern continents has constrained their ecological opportunities relative to the placental mammals that currently dominate the northern continents. This idea, however, fails to explain the observation that extant placental orders had already appeared by the Eocene, at which time metatherian mammals still persisted on northern continents. Indeed, as noted earlier, metatherians outnumbered eutherians in North America during an extensive portion of the Cretaceous. Thus, for a significant section of their Cenozoic evolutionary histories (until the disappearance of Laurasian metatherians in the Miocene), Metatheria declined and Eutheria thrived, despite both clades being exposed to the same changing environments.

A few recent studies have begun to quantify metatherian diversity through time, focusing on key localities or intervals (Cifelli et al. 2014; Williamson et al. 2014; Wilson 2013, 2014; Zimicz 2014; Grossnickle and Newham 2016) or specific clades (e.g., koalas [Black et al. 2014] and sparassodonts [Prevosti et al. 2013]). However, to date, all of these studies (with the exception of three recent papers focusing on the Cretaceous-Paleogene interval: Wilson 2014; Grossnickle and Newham 2016; Longrich et al. 2016) have examined raw taxonomic diversity, without considering biases in the fossil record. The fossil record is inherently incomplete, as fossilization of organisms only occurs under very particular environmental conditions (Padian and Clemens 1985; Badgley 2003; Vermeij and Leighton 2003; Kalmar and Currie 2010). There is also general agreement that the fossil record includes a number of potentially nonrandom sampling biases reflecting both geological and anthropogenic factors (Alroy et al. 2001, 2008; Peters and Foote 2001; Crampton et al. 2003; Fastovsky et al. 2004; Smith and McGowan 2007; Uhen and Pyenson 2007; Fröbisch 2008; Butler et al. 2009, 2011; Wall et al. 2009; Alroy 2010; Benson et al. 2010; Sahney et al. 2010; Benson and Butler 2011; Benton et al. 2011; Mannion et al. 2011, 2015; Lloyd and Friedman 2013; Pearson et al. 2013; Smith and Benson 2013; Newham et al. 2014; Nicholson et al. 2015). For example, sedimentary rocks in North America and Europe have been more thoroughly searched 
for fossils than elsewhere in the world, because paleontology has a more extensive research history in those regions and the necessary resources for fieldwork have historically been more readily available. As a result, the dating of sedimentary deposits, and the systematics of the fossil taxa they contain, are generally better understood in Europe and North America than elsewhere (e.g., Smith and McGowan 2007; Upchurch et al. 2011). Moreover, formations located on either side of major extinction events or from other geologically significant periods of time are likely to receive greater attention from paleontologists, and thus can be better sampled than portions of the fossil record that are perceived to be less "spectacular" (e.g., the apparent peak in dinosaur diversity and sampling, observed shortly before the Cretaceous/Paleogene boundary potentially reflects intense interest in the leadup to the mass extinction; Upchurch et al. 2011). Thus, fluctuations in diversity observed directly in the fossil record could simply reflect variation in sampling intensity rather than true evolutionary change. Consequently, previous attempts to establish patterns in metatherian diversity should be treated with caution, because they have generally not accounted for potential biases in the fossil record.

Two recent works have analyzed aspects of metatherian diversity using techniques that attempt to account for the uneven sampling of the fossil record (Grossnickle and Newham 2016; Longrich et al. 2016). These studies, however, did not examine metatherian diversity in its own right, but rather included this clade in larger data sets dealing with either all mammals (Longrich et al. 2016) or Theria (Grossnickle and Newham 2016). Moreover, both of these analyses focused on the $\mathrm{K} / \mathrm{Pg}$ mass extinction, and that by Longrich et al. (2016) dealt solely with North America. Thus, while both of these studies yield valuable insights into metatherian diversity (see "Discussion"), they do not provide the global and regional perspectives over an extended portion of evolutionary history presented by the current work.

In short, despite the increasing variety and complexity of approaches to elucidating macroevolutionary patterns in past diversity (discussed in detail below), no robust, comprehensive, and quantitative analysis of metatherian diversity spanning their evolutionary history is currently available. To address this deficit, we present here a new data set on metatherian fossil occurrences based on an extensive survey of the literature. This data set is analyzed using standard rarefaction and a modified version of shareholder quorum subsampling (SQS) to produce sampling-corrected global paleodiversity estimates for metatherians throughout the Cretaceous to Pliocene interval. Finally, the resulting inferences concerning metatherian paleodiversity are placed in the wider context of previous studies of the group and global environmental change during the Cretaceous and Cenozoic.

\section{Materials and Methods}

\section{Taxonomic Level}

The choice of taxonomic level for diversity analysis has important implications for studies of extinction and origination rates, as species are shorter lived than genera, and genera are in turn shorter lived than families. Diversity is analyzed here at the genus level, because this information is available for almost every published fossil. Moreover, the use of genera can increase the amount of occurrence data available for paleodiversity analysis, because it allows the inclusion of specifically indeterminate fossils (e.g., Mannion et al. 2015).

\section{Data Collection and Management}

Data within the Paleobiology Database (PaleobioDB: https://paleobiodb.org/\#), while substantial for certain taxonomic groups (e.g., marine invertebrates and dinosaurs), are lacking where mammals are concerned, particularly for those located outside the United States and for the post-Paleocene Cenozoic. Speed of data entry into the PaleobioDB and restrictions on the entry format for data, made the creation of an Access database (from which our data sets were extracted) a faster and more flexible approach here. It is the authors' hope that the current data set will be entered into the PaleobioDB at a later date for the benefit of the wider paleontological community.

A comprehensive data set detailing published metatherian fossil finds (i.e., specimens) 
has been collated, including: genus name; fossil site; geographic location; and geological epoch and subepoch (where possible). Several resources were used to search for information on fossil finds. First, the key words "Metatheria," "Metatherian," "Marsupial," "Fossil," "Palaeontology," and "Paleontology" were searched for within ISI Web of Knowledge and Google Scholar, and resources at the Natural History Museum library, London, and the PaleobioDB were also examined. Second, the reference lists of the resulting papers were then searched for relevant publications, and this process was repeated until no additional references were found. Journals in which metatherian fossil publications frequently occurred were also examined by index for any other relevant papers. The database includes all such papers published up to and including December 2016.

Taxonomic names have been corrected where reclassification literature exists, although validity of names was specifically checked for very old publications. Misclassification is, of course, a possibility in some cases because of human error. In the case of older publications and those describing plentiful cave deposits, where information regarding numbers of individual fossils is not explicit, estimates for the minimum number of individuals were recorded according to the available data.

Data not cited in the literature, for example, museum collections databases, could not be included in this study, because they would bias data toward collection efforts by museums with good online resources. Further, the classifications of these specimens have not been peer reviewed, unlike published taxa/specimens, and are thus potentially more prone to misidentification.

Metatherian fossil finds were recorded from their first appearance ( 125 Ma) until the end of the Tertiary, specifically excluding the Quaternary record in order to reduce the impact of the "pull of the Recent" (e.g., Jablonski et al. 2003). Excluding Quaternary fossils also restricted the effect of an overwhelming volume of subfossil taxa at many cave deposit sites, which is not seen anywhere else in the fossil record.

The metatherian fossil records of Asia (13 genera), Europe (8 genera), Africa (1 genus), and Antarctica (7 genera) are extremely limited and thus cannot be subjected to bias-correction techniques to provide region-specific estimates. However, the global (333 genera), North American (44 genera), South American (143 genera), and Australian (Australia, New Guinea, and adjacent islands are here in referred to as "Australian"; 129 genera) records are large enough to be robustly analyzed. Tables 1A and 1B show the number of genera and fossil sites broken down by time bin for the epoch and subepoch data sets. The full data set, comprising 1928 and 1861 occurrences at the epoch and subepoch levels, respectively, for 333 metatherian genera, and the bibliography of the references used to construct this data set, are provided in the Supplementary Data.

\section{Time Bins}

Unfortunately, the precision of geological dates for localities bearing metatherian fossils, and mammals more generally, is often limited to the epoch level. Epochs from the Late Cretaceous through to the end Neogene are highly uneven in length, ranging from $34.5 \pm$ 1.2 Ma (Late Cretaceous) to 2.75 Ma (Pliocene). Geologic stages for this interval are much more even, with a maximum difference of only $\sim 10.5$ Myr between the Campanian and Piacenzian, but many fewer metatherian fossil sites are dated to the stage level than to the epoch level. However, the ages of some fossil sites, although not assigned to a specific geological stage, have been estimated with a resolution greater than epoch level, that is, "middle Miocene" or "early Eocene"; these designations will be referred to as "subepochs" herein. Stage data can easily be grouped into these categories, providing a reasonable compromise between maximum time frame resolution and the inclusion of a greater number of fossils in the data set.

Local units such as continent-specific land mammal ages were avoided here, mainly because they are referred to in the literature considerably less often than epochs or stages, limiting their usefulness. They also lack definitive correlation across continents. Furthermore, they are based on occurrences of different mammal groups and are thus not independent of mammal diversity. Metatherian fossils that have previously been dated to South American, North American, or European land mammal 
TABLE 1. Number of genera and fossil sites for the global, North American, South American, and Australian data sets by epoch and subepoch. NA, not applicable, as there are no genera/sites.

\begin{tabular}{|c|c|c|c|c|c|c|c|c|c|}
\hline \multirow[b]{2}{*}{ A. Epoch } & \multirow[b]{2}{*}{ Myr } & \multicolumn{2}{|c|}{ Global } & \multicolumn{2}{|c|}{ North America } & \multicolumn{2}{|c|}{ South America } & \multicolumn{2}{|c|}{ Australia } \\
\hline & & Genera & Sites & Genera & Sites & Genera & Sites & Genera & Sites \\
\hline Early Cretaceous & 44.5 & 8 & 13 & 7 & 12 & NA & NA & NA & NA \\
\hline Late Cretaceous & 34.0 & 33 & 257 & 26 & 232 & NA & NA & NA & NA \\
\hline Paleocene & 10.0 & 22 & 76 & 5 & 64 & 17 & 10 & NA & NA \\
\hline Eocene & 22.1 & 79 & 290 & 9 & 182 & 59 & 46 & 4 & 2 \\
\hline Oligocene & 10.9 & 55 & 142 & 3 & 46 & 23 & 21 & 25 & 41 \\
\hline Miocene & 17.7 & 137 & 239 & 1 & 8 & 56 & 106 & 77 & 94 \\
\hline \multirow[t]{2}{*}{ Pliocene } & 2.8 & 63 & 75 & NA & NA & 13 & 24 & 50 & 51 \\
\hline & & \multicolumn{2}{|c|}{ Global } & \multicolumn{2}{|c|}{ North America } & \multicolumn{2}{|c|}{ South America } & \multicolumn{2}{|c|}{ Australia } \\
\hline B. Subepoch & Myr & Genera & Sites & Genera & Sites & Genera & Sites & Genera & Sites \\
\hline Late Early Cretaceous & 31.0 & 8 & 13 & 7 & 12 & NA & NA & NA & NA \\
\hline Early Late Cretaceous & 13.7 & 10 & 21 & 7 & 9 & NA & NA & NA & NA \\
\hline Late Late Cretaceous & 20.3 & 28 & 234 & 24 & 223 & NA & NA & NA & NA \\
\hline Paleocene & 10.0 & 22 & 76 & 5 & 64 & 13 & 10 & NA & NA \\
\hline Early Eocene & 14.8 & 53 & 201 & 7 & 150 & 36 & 23 & 4 & 2 \\
\hline Late Eocene & 7.3 & 38 & 84 & 6 & 30 & 30 & 23 & 0 & 0 \\
\hline Oligocene & 10.9 & 55 & 142 & 3 & 46 & 23 & 21 & 25 & 41 \\
\hline Early Miocene & 7.0 & 67 & 93 & 1 & 6 & 27 & 56 & 37 & 26 \\
\hline Middle Miocene & 4.5 & 57 & 61 & NA & NA & 21 & 24 & 34 & 30 \\
\hline Late Miocene & 6.3 & 41 & 37 & NA & NA & 22 & 24 & 19 & 13 \\
\hline Pliocene & 2.8 & 63 & 75 & NA & NA & 13 & 24 & 50 & 51 \\
\hline
\end{tabular}

ages were assigned to the subepoch time bins used here. Where a land mammal age spanned two subepoch bins, it was assigned to the bin covering the majority of its time span.

Cave deposits and fossils that have been transported are difficult to date with much precision, as they are not necessarily the same age as surrounding rocks. For these reasons, the temporal resolution of this study is limited by information available in the literature. There are very few radiometric dates in the literature that describe the fossils themselves. Where formations and beds were given, a literature search was conducted to find more information. Websites such as the U.S. Geological Survey (2013) and the Australian Stratigraphic Units Database (Geoscience Australia and Australian Stratigraphy Commission 2013) were used to fill in these missing data, and for many sites the University of California Museum of Paleontology collections database (2016) held more information than published with the original descriptions of taxa.

It has been argued that subsampling approaches should not be performed on time bins of unequal length because of the intuitive link between time-bin duration and the number of observable taxa (Raup 1975; Alroy et al. 2001; Alroy 2008). Circumvention of this problem by standardizing time-bin length, however, is limited in practice by the resolution to which fossils are dated (Alroy 2008). In any case, there is some evidence that this issue might not be as serious a concern as previously thought. Mannion et al. (2011) found that taxic diversity and sample number shared no statistically significant correlations with stage or epoch length for their sauropod data. The same result was found by Butler et al. (2011) for data sets on the occurrences of all dinosaurs. Nevertheless, to investigate whether uneven time-bin length distorts the true diversity signal for metatherians, we tested for correlations between raw diversity and time-bin length (Supplementary Data). Data were log transformed, and Pearson correlations were then calculated using the 'Hmisc' package (Harrell and Dupont 2013) in R, Version 3.1.2 (R Development Core Team 2016).

Corrections for Uneven Fossil-Record Sampling Units of Sampling.-A key step in standard rarefaction and SQS is the repeated random 
drawing of subsamples of the total data set, followed by calculation of the diversity represented within the subsamples. This means that diversity data (e.g., genera or species) have to be linked to units of sampling such as specimens, localities, collections, publications, etc. (Alroy et al. 2001, 2008; Bush et al. 2004; Alroy 2010). However, consistent grouping of the metatherian fossil record into "localities" or "collections" is challenging for several reasons. Finds from several field seasons are frequently grouped together, especially when the paper describes a fauna or names a new species (e.g., Travouillon et al. 2010). On other occasions, particularly in older papers, but also often for more recent fossils that are not found in lithified sediments, the exact location of the specimen is not well defined (e.g., Flannery et al. 1987; Pledge 1987). Quite frequently, fossils are assigned to a fauna rather than to a lithology or exact site (e.g., Muirhead et al. 1997; Hocknull 2005). The varying detail among papers also creates the potential for overlap or separation of sampling units. For these reasons, site names and/or descriptions are more consistently available in the literature. Hence, we used fossil site names and/or location descriptions as the randomly drawn units for our subsampling methods.

The subepoch-level data used in the rarefaction and SQS analyses described in the following sections are presented in Supplementary Data.

Rarefaction.-Rarefaction, a relatively simple subsampling technique, has been used extensively in taxonomic diversity research (e.g., Raup 1972, 1975, 1979; Miller and Foote 1996; Alroy et al. 2001, 2008; Fastovsky et al. 2004; Mannion et al. 2011). It involves drawing a random sample of individuals (individual based) or groups of individuals (sample based) from the entire data set to generate an expected number of taxa according to the level of sampling intensity (Raup 1975; Miller and Foote 1996).

Here we conducted sample-based rarefaction by randomly selecting fossil sites up to the maximum number of sites in the time bin with the fewest fossil sites, using bespoke code (Supplementary Text 1) written in R, Version 3.1.2 ( $\mathrm{R}$ Development Core Team 2016). The number of genera present in these localities was then tallied to give a subsampled diversity estimate. This subsampling for each time bin was repeated 1000 times, and the mean genus count was plotted to produce a diversity curve. The $95 \%$ confidence intervals around the mean were also calculated.

SQS.-SQS is an alternative, more sophisticated sampling standardization method (Alroy 2010) that has been widely used in recent years (e.g., Newham et al. 2014; Brusatte et al. 2015; Mannion et al. 2015; Nicholson et al. 2015; Grossnickle and Newham 2016). SQS builds on the principle of rarefaction, but differs from the latter by taking into account the relative abundance (also known as the "frequency") of each taxon. For each time interval, taxa are assigned frequency values according to the proportion of collections lists in which they appear. Collections lists are drawn in the same manner as detailed above until a userdefined threshold or "quorum" (the summed frequency of the unique taxa drawn) is reached. Additionally, to avoid biasing the results against intervals with particularly poor sampling, each time bin is assigned a value that estimates "coverage" (Good's $U$ ) that reflects the proportion of "singleton" taxa (Good 1953). Good's $U$ ranges between 1 and 0 , where a value of 1 means that all taxa in the time bin are known from at least two collections, and a value of 0 means that all taxa are each known only from one collection (i.e., they are singletons). Thus, time bins with lower Good's $U$ values can be regarded as having poorer coverage (i.e., they are more poorly sampled), and so we should sample them more heavily to compensate for this. Good's $U$ is thus used to correct the target quorum in order that intervals with poor initial coverage are sampled more heavily.

To account for further biases, two adjustments are then made that potentially have the most impact on small and idiosyncratic data sets (Alroy 2010: p. 1217). First, the most common taxon in each time bin, if drawn during sampling, is excluded from the frequency calculation, though still counted in the diversity estimation. Second, singletons belonging to the most diverse "collection" in any one time bin are excluded from the singleton count used to calculate coverage. This modification aims to ameliorate the distortions caused by fossil sites with exceptional preservation (Lagerstätten). 
The latter modification is needed, because rare taxa are more likely to be preserved in Lagerstätten than elsewhere, thus lowering the apparent coverage of that time bin. This could result in genuinely well-sampled time bins with Lagerstätten appearing to be poorly sampled because of their lower Good's $U$ scores, causing SQS to oversample them and therefore produce an artificially high peak in estimated diversity.

Alroy (2010) additionally adjusted the results of SQS by applying a "three-timer" equation to avoid the Signor-Lipps effect (Signor and Lipps 1982) and the pull of the Recent. This involves estimating the sampling probability of each time bin using the following equation:

$$
P_{s}={ }^{3} t /\left({ }^{3} t+{ }^{P} t\right)
$$

where $P_{\mathrm{s}}$ is the sampling probability, ${ }^{3} t$ is the number of three-timer taxa (i.e., taxa that occur in the time bin in question, as well as in the time bins immediately before and after), and $\mathrm{P}_{t}$ is the number of part-timers (i.e., taxa appearing in the bins immediately before and after but not in the bin in question).

Although accounting for these factors is important, the way in which the adjustments are executed in Alroy's (2010) methodology might oversimplify some aspects of variation in sampling. For example, there is no reason to expect that there would be only one Lagerstätte site in each time bin, or that every time bin includes a Lagerstätte. To better reflect the metatherian fossil record, we therefore created diversity curves globally and by continent using Alroy's SQS method with the following modification. As an alternative to Lagerstätten, "prolific" sites are determined a priori by taking into account two possible indicators of exceptional preservation: number of specimens and number of genera recorded for each fossil site. These measures are calculated for each site as a proportion of the total count of each for the entire data set and summed to give one value for each site. For example, suppose site $X$ has produced 10 genera and 1000 specimens, and the total number of genera and specimens in the data set is 100 and 5000, respectively. Site $X$ has 0.1 of the genera and 0.2 of the specimens, and so has a total score of 0.3. The sites for which this value is greater than 3 standard deviations away from the mean are considered prolific sites. These sites are then treated in the same manner as Alroy's "most diverse site" in each time bin by excluding their singleton occurrences in the coverage calculation.

The target sampling level for all analyses was set at 0.3, except for South America, which was set at 0.1 due to extremely low coverage (Good's $U$ is 0.16 ) in the Paleocene (although see diversity curve set at 0.3 for relative comparison of Eocene-Pliocene in Supplementary Data). A target of 0.3 is lower than recommended by Alroy (2010), who advised that quorum levels of $0.4-0.7$ were likely to produce the best results. However, the frequency of the North American Oligocene genus Herpetotherium is 0.68: once this most abundant taxon is excluded (and given that Good's $U$ is nearly 1 for this region and time bin), the target sampling level cannot be higher than 0.3. In addition, as there is only one genus (again Herpetotherium) in the early Miocene of North America, SQS cannot be used to estimate diversity for this time bin. The Eocene of Australia was also excluded from SQS analysis, as Good's $U$ is 0. All SQS analyses were conducted in R, Version 3.1.2, and code with the "prolific site" modification is provided in Supplementary Text 2.

\section{Taxonomic Rates and Sampling Probability}

Taxonomic origination and extinction rates, along with sampling probability, are crucial metrics for understanding diversity patterns in evolution. Here we employed the method devised by Alroy (2008), that standardizes data using three-timer rates. This method is based on the relative proportions of taxa appearing before and after the interval in question, as in the previously mentioned rates calculations, accounting for the overall sampling probability as follows:

$$
\begin{gathered}
\text { extinction rate }=\log \left({ }^{2} t_{i} /{ }^{3} t\right)+\log \left(P_{\mathrm{s}}\right) \\
\text { origination rate }=\log \left({ }^{2} t_{i}+1 /{ }^{3} t\right)+\log \left(P_{\mathrm{s}}\right)
\end{gathered}
$$

where ${ }^{2} t_{i}$ represents the number of taxa sampled immediately before and within the $i$ th bin; ${ }^{2} t_{i+1}$ represents the number of taxa 
within and immediately after the $i$ th bin; and ${ }^{3} t$ and $P_{\mathrm{s}}$ as in eq. 1 . The calculation for sampling probability assumes that sampling standardization has been successful (thus $P_{\mathrm{s}}$ is constant) and that it is not systematically correlated with origination or extinction rates. However, the approach in Alroy (2008) proceeds to correct for possible sampling discrepancies through time by calculating $P_{\mathrm{s}}$ according to time bin, that is, using values of ${ }^{3} t$ and ${ }^{\mathrm{P}} t$ specific to the $(i+1)$ th and $(i-1)$ th bins for extinction and origination, respectively.

This method for calculating origination (eq. 3 ) and extinction rates (eq. 2) improves upon that of Foote (2001), in that it reduces the Signor-Lipps effect. However, this effect might not always be significant; for example, in their study of size-related evolutionary rates in Neogene Old World mammals, Liow et al. (2008) used Foote's (2001) equation without correcting for forward and backward survivorship, because preservation rate biases were small, thus reducing the Signor-Lipps effect through time and not distorting the overall pattern of rates. Nevertheless, for larger time periods and global studies, such as the analyses here, preservation rates are an important consideration in the accurate estimation of taxonomic rates. Furthermore, Alroy's technique is computationally simpler than Foote's modeling approach and probably more accurate, because it is based on a larger amount of real data rather than just the first and last appearances of taxa.

\section{Results}

\section{Time-Bin Length versus Observed Diversity}

At the epoch level, no significant correlations were found between time-bin length and raw diversity for the global, North American, or South American data sets (Supplementary Data). The Australian fossil record did not span enough epochs to calculate a correlation between time-bin length and raw diversity. A similar absence of correlation between time-bin length and diversity occurs in all subepoch data sets, including that for Australia (Supplementary Data).

Therefore, although caution is required, these results suggest that it is valid to analyze the diversity of Metatheria using the available time bins of unequal length. In any case, as we noted earlier, any analysis of metatherian diversity currently requires use of these broad and uneven time bins pending more precise dating of much of this clade's fossil record.

\section{Metatherian Raw Taxic Diversity}

Raw metatherian taxic diversity increases from their first appearance in the Early Cretaceous to the end of the Pliocene, with notable peaks in the latest Cretaceous, early Eocene, early Miocene, and Pliocene and troughs in the Paleocene, late Eocene, and late Miocene (Fig. 1A). There is a dramatic drop in North American raw taxic diversity in the Paleocene following a considerable peak in the latest Cretaceous (Fig. 1B). Raw South American diversity peaks in the early Eocene, falls during the Oligocene, and rises again in the early Miocene. Diversity declines in the middle Miocene and is lowest in the Pliocene (Fig. 1C). Australian raw taxic diversity increases greatly between the Eocene and Oligocene, peaks in the early Miocene, declines throughout the remainder of the Miocene, and rises again to a maximum in the Pliocene (Fig. 1D).

\section{Rarefaction}

In contrast to the raw global diversity curve (Fig. 1A), the subepoch-resolution global rarefaction curve (Fig. 2A) shows a gentle rise between the Paleocene and Oligocene, although a similar peak in the early Miocene is shown. Diversity declines in the middle Miocene, rises in the late Miocene, and is followed by a slight drop to the Pliocene. The rarefaction analysis for North America (Fig. 3A) shows a rise from the early Late Cretaceous to a peak in the latest Cretaceous, a steep fall in the Paleocene, a slight rise to an Eocene plateau, and then a subsequent fall to the Miocene. The South American rarefaction curve (Fig. 4A) shows a rise to a maximum in the early Eocene and then a general decline in diversity through time, but with a slight rise in diversity in the late Miocene. Rarefaction of the Australian metatherian record (Fig. 5A) depicts diversity rising from the Oligocene to the early Miocene, falling in the middle 


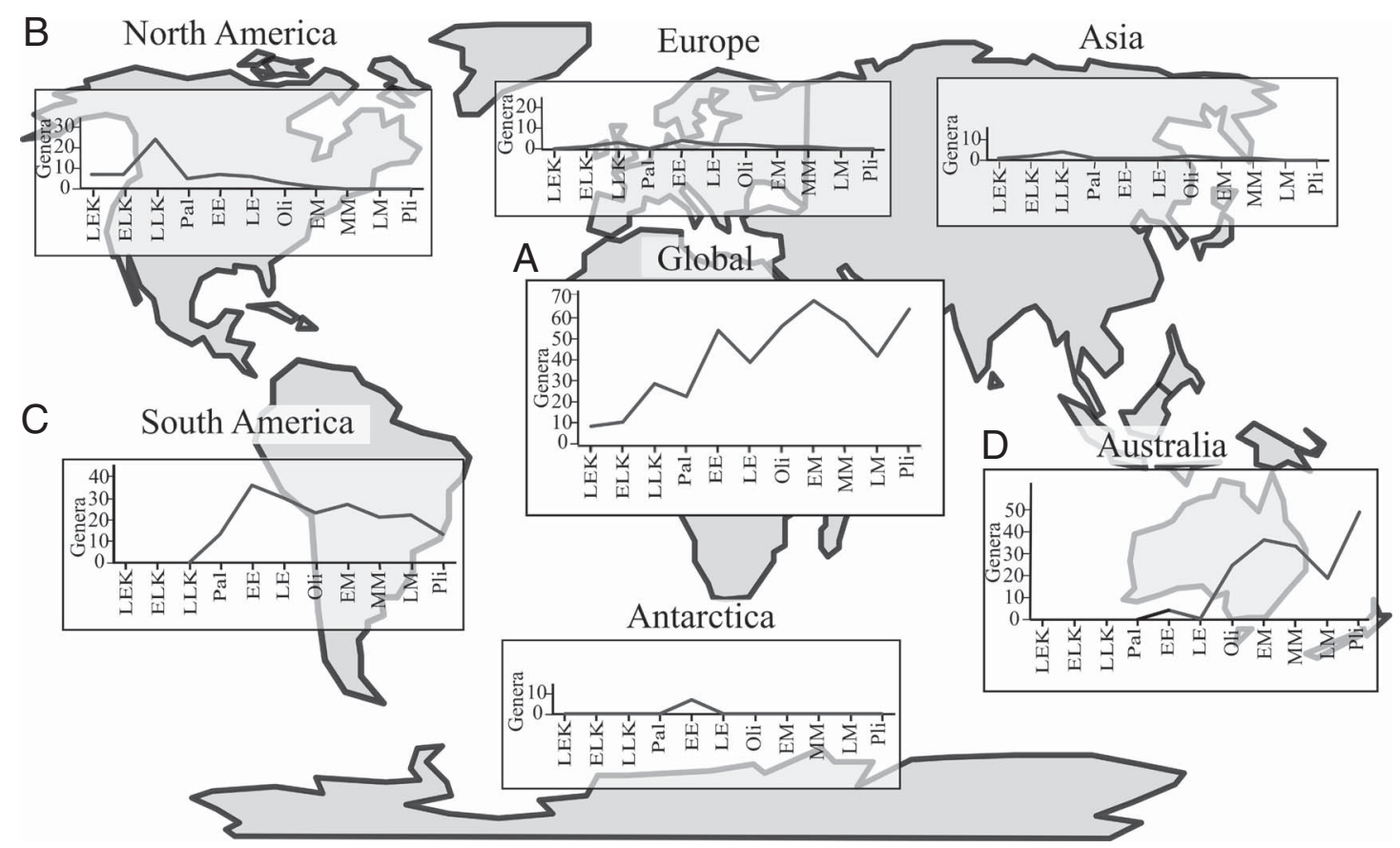

FIGURE 1. Raw genus counts for Metatheria through time by subepoch for each continent and globally. EE, early Eocene; EK, Early Cretaceous; ELK, early Late Cretaceous; EM, early Miocene; LE, late Eocene; LEK; late Early Cretaceous; LLK, late Late Cretaceous; LK, Late Cretaceous; LM, late Miocene; MM, middle Miocene; Oli, Oligocene; Pal, Paleocene; Pli, Pliocene.

Miocene, rising again in the late Miocene, and falling in the Pliocene.

\section{SQS}

As with rarefaction, the SQS curves bear little resemblance to raw data curves (compare Figs. 1A and 2B). The global SQS curve (Fig. 2B) also contrasts with that produced by rarefaction (Fig. 2A), most notably in the Paleocene, where the former suggests that there was a rise in diversity from the Late Cretaceous. The SQS reconstruction of metatherian diversity patterns includes a plateau through the Late Cretaceous, the sharp rise to the Paleocene just noted, and a gentler rise to the early Eocene and fall to the late Eocene. Diversity then rises steeply to its maximum in the early Miocene, decreases sharply to a late Miocene trough, and then rises into the Pliocene.

For the North American record, SQS diversity rises from the Early Cretaceous to a Late Cretaceous plateau before dropping in the Paleocene (Fig. 3B). Diversity rises to a late
Eocene peak before falling in the Oligocene and early Miocene (Fig. 3B). The South American SQS curve (Fig. 4B) begins with high diversity in the Paleocene, rising slightly in the early Eocene, and then decreasing continually to its lowest diversity in the Pliocene. The Australia SQS diversity curve (Fig. 5B) shows an increase in diversity between the Oligocene and its early Miocene peak. Diversity declines to the late Miocene but then rises again in the Pliocene.

\section{Origination, Extinction, and Preservation}

Origination and extinction rates (Table 2) were calculated for the early and late Eocene; Oligocene; and the early, middle, and late Miocene. Origination rate and extinction rate could not be calculated for the Late Cretaceous or Paleocene using the method of Alroy (2008), because there are no three-timer $\left({ }^{3} t\right)$ genera (i.e., taxa that appeared before, after, and in the Paleocene time bin). Although Alroy (2015) has more recently proposed a new method that 


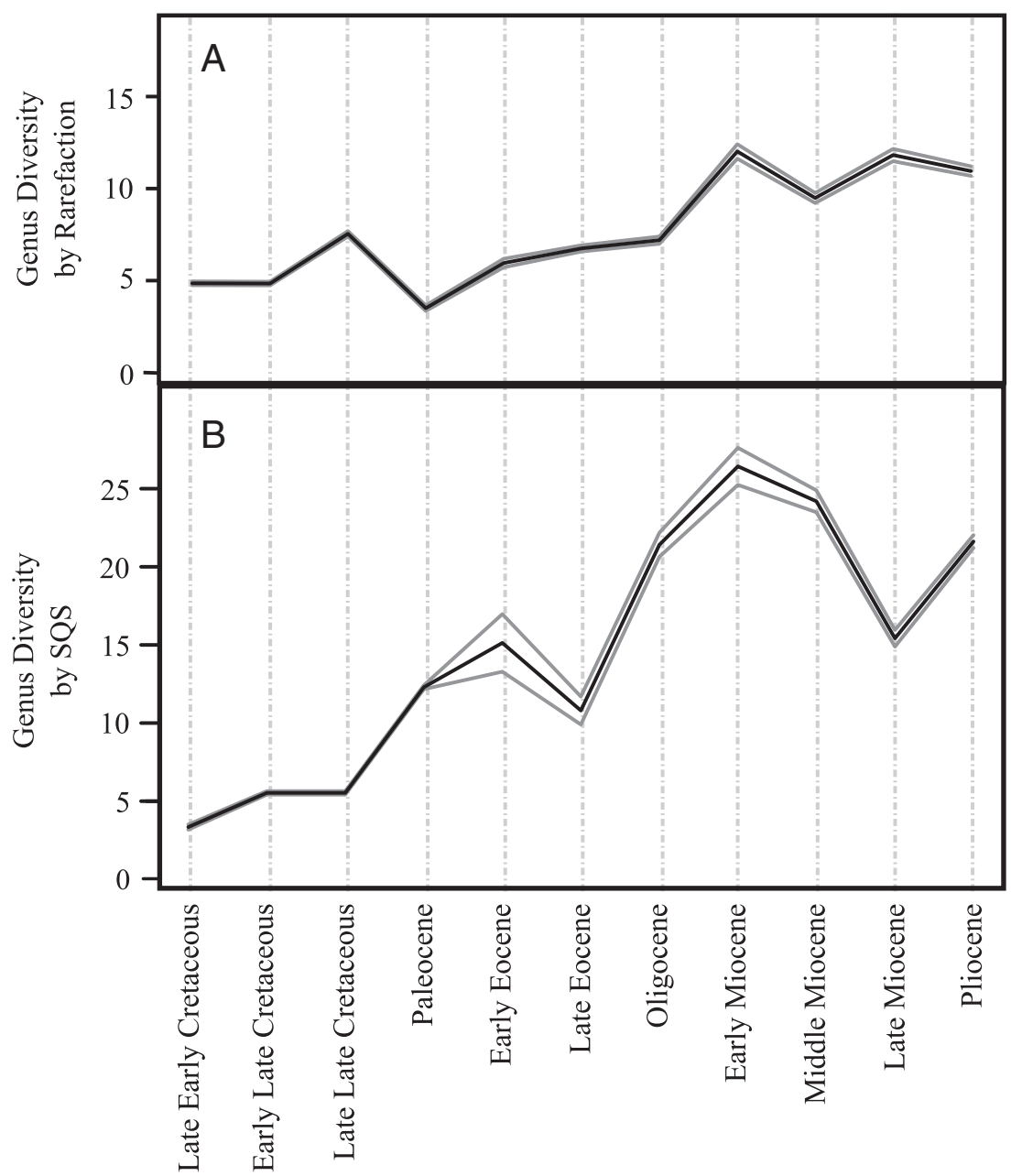

FIGURE 2. Classic rarefaction (A) and SQS sampling at 0.3 quorum level (B) of global metatherian genus diversity by number of fossil sites by subepoch. Solid gray lines represent $95 \%$ confidence intervals.

does not rely on ${ }^{3} t$ genera, this is even less suitable for our data (see Supplementary Data for comparison of results). Origination and extinction rates also could not be calculated for the late Early Cretaceous and Pliocene time bins, because there are no earlier or later data, respectively, in our data set. Of the intervals for which we could calculate rates, origination rate was highest in the early Eocene and lowest in the early Miocene. Extinction rate was highest in the late Miocene and lowest in the early Miocene.

Preservation rates (Table 2 and Supplementary Data) could not be calculated using Alroy's (2008) method for the Late Cretaceous or Paleocene because of the lack of three-timers already mentioned. Where this rate could be estimated, it was lowest in the late Miocene and Oligocene $(50 \%)$. Rates of preservation were highest in the early Miocene $(86 \%)$ and early Eocene (100\%), where there are no genera present in the Paleocene or late Eocene that are not also represented in the early Eocene.

\section{Discussion}

\section{Methodological Issues}

Despite some similarity between the two sample standardization methods applied here, there are several clear discrepancies, as noted earlier. The global Paleocene, late Eocene, and late Miocene (Fig. 2), North American early Late Cretaceous and late Eocene (Fig. 3), and 


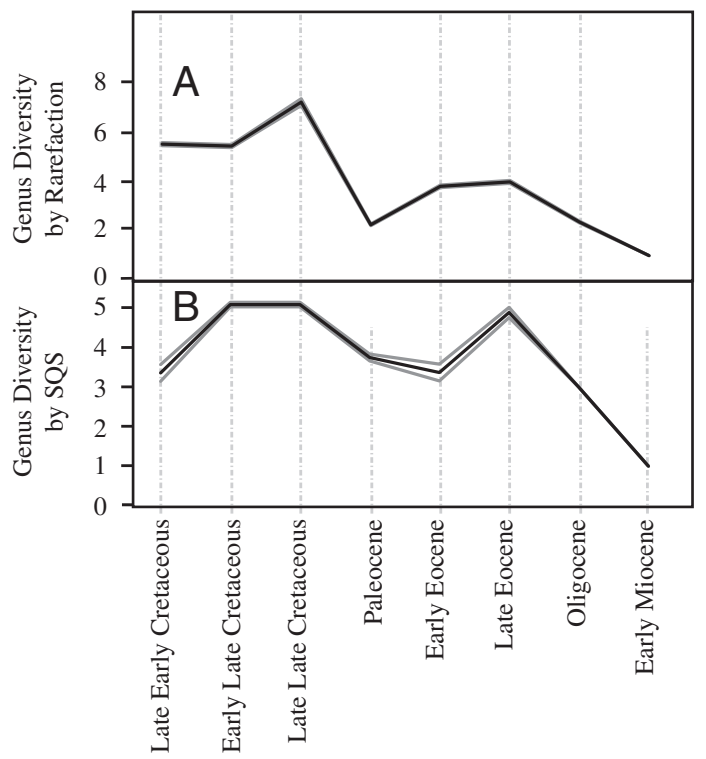

FIGURE 3. Classic rarefaction (A) and SQS sampling at 0.3 quorum level (B) of North American metatherian genus diversity by number of fossil sites by subepoch. Solid gray lines represent $95 \%$ confidence intervals.

the Australian late Miocene (Fig. 5) diversity patterns are reconstructed rather differently by the two approaches. These differences raise the question of whether one of the methods, and therefore its results, should be preferred over the other. If all genera occurred equally frequently (i.e., within the same proportion of fossil sites) in the time bin in question, or each fossil site comprised groups of genera with similarly varied frequencies and there were the same proportion of singletons in each time bin, then SQS and rarefaction would produce the same diversity curves. As this is clearly not the case (Fig. 6 and Supplementary Data), it is pertinent to investigate the nature of species occurrence frequencies in order to understand which method produces a more accurate estimate of diversity.

Two key methodological steps particular to SQS probably account for these discrepancies in the results: (1) sampling to a standard "quorum" level based on the cumulative occurrence frequencies of unique taxa drawn; and (2) correction of the sampling level for each time bin depending on the proportion of single-occurrence taxa (Good's $U$ ). Distribution of genus-occurrence frequencies through time is illustrated by the histograms in Figure 6.

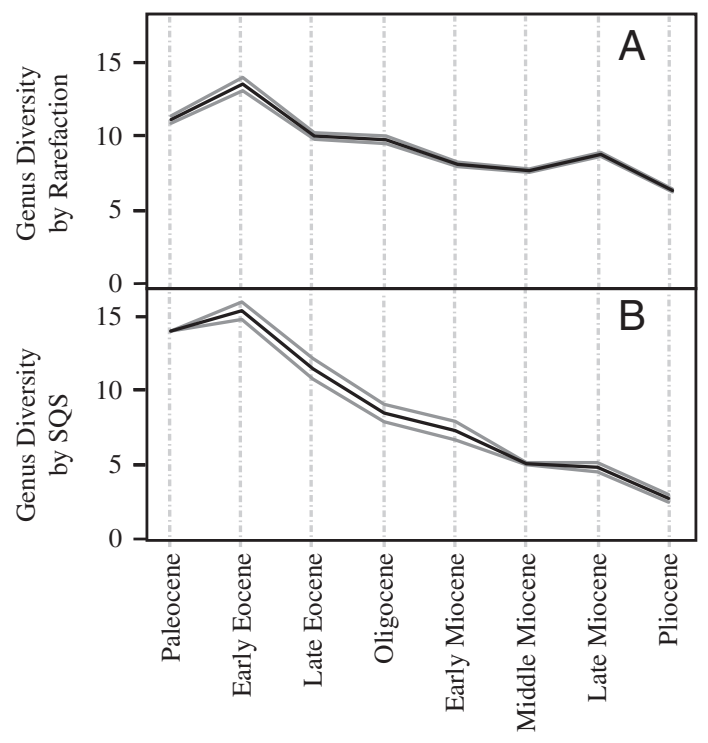

FIGURE 4. Classic rarefaction (A) and SQS sampling at 0.1 quorum level (B) of South American metatherian genus diversity by number of fossil sites by subepoch. Solid gray lines represent $95 \%$ confidence intervals.

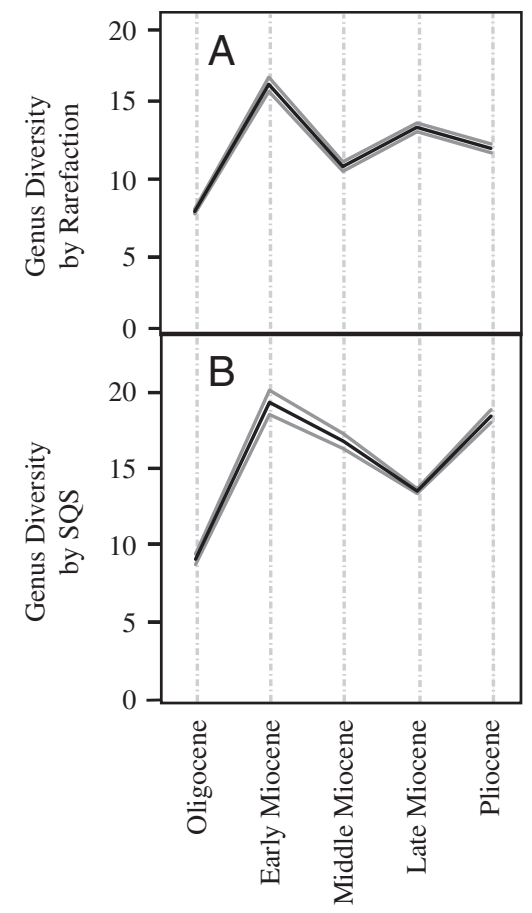

FIGURE 5. Classic rarefaction (A) and SQS sampling at 0.3 quorum level (B) of Australian metatherian genus diversity by number of fossil sites by subepoch. Solid gray lines represent $95 \%$ confidence intervals.

In the global and North American metatherian record, the Paleocene distribution of occurrence frequencies explains the difference in 
SQS and rarefaction results. The majority of sites have only one or two unique genera, and Peradectes is present in over half these sites, while most other genera have frequencies of less than 0.02. As the most frequent genus, Peradectes is excluded from the frequency calculation, and thus many genera must be sampled to reach the target cumulative frequency. The North American fossil record also shows varying occurrence frequencies for genera through time (Fig. 6). The proportion of singleton genera not belonging to prolific sites is relatively high in the North American early Late Cretaceous (Fig. 6), thus the target sampling level is higher than for other times. Similarly, in the Australian record, the proportion of singleton genera varies through the Miocene and Pliocene, with the middle
TABLE 2. Global preservation, origination, and extinction rates by epoch. Rates are calculated according to Alroy (2008). Rates marked as not applicable (NA) where they could not be calculated.

\begin{tabular}{lccc}
\hline \hline & Preservation & $\begin{array}{c}\text { Extinction } \\
\text { rate }\end{array}$ & $\begin{array}{c}\text { Origination } \\
\text { rate }\end{array}$ \\
\hline $\begin{array}{l}\text { Early Late } \\
\quad \text { Cretaceous }\end{array}$ & $\mathrm{N} / \mathrm{A}$ & $\mathrm{N} / \mathrm{A}$ & $\mathrm{N} / \mathrm{A}$ \\
$\begin{array}{l}\text { Late Late } \\
\quad \text { Cretaceous }\end{array}$ & $\mathrm{N} / \mathrm{A}$ & $\mathrm{N} / \mathrm{A}$ & $\mathrm{N} / \mathrm{A}$ \\
$\begin{array}{l}\text { Paleocene } \\
\text { Early Eocene }\end{array}$ & $\mathrm{N} / \mathrm{A}$ & $\mathrm{N} / \mathrm{A}$ & $\mathrm{N} / \mathrm{A}$ \\
Late Eocene & 1.00 & 1.39 & 2.40 \\
Oligocene & 0.80 & 0.55 & 0.52 \\
Early Miocene & 0.50 & 0.90 & 1.11 \\
Middle Miocene & 0.86 & 0.39 & 0.51 \\
Late Miocene & 0.60 & 1.26 & 0.72 \\
\hline
\end{tabular}

Miocene and Pliocene having higher proportions than the late Miocene (Fig. 6). As a result, SQS samples the late Miocene to a lower

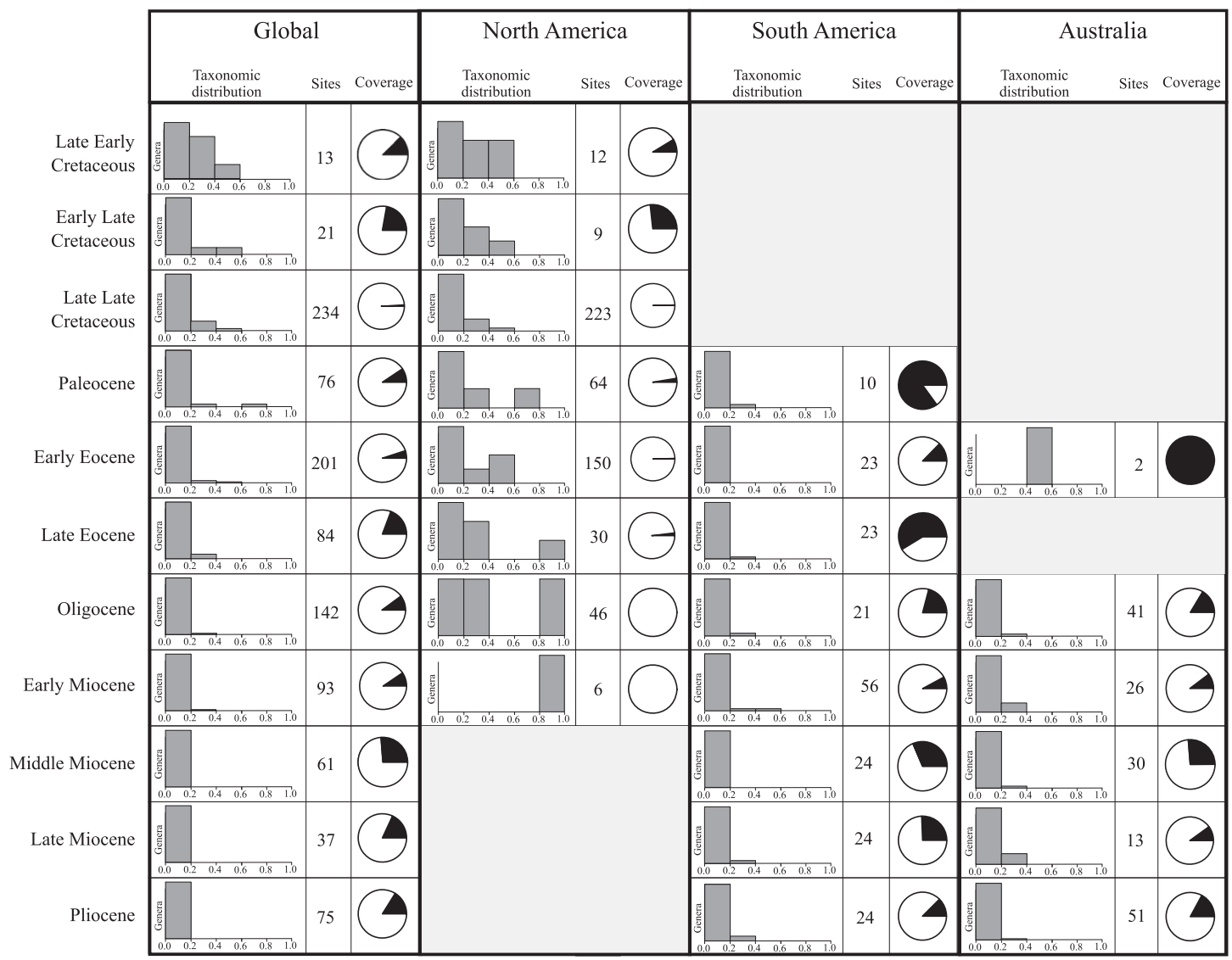

FIGURE 6. Summary of global, North American, South American, and Australian fossil record by subepoch. Bar chart vertical axes represent relative numbers of genera within each subepoch; horizontal axes represent proportion of the total number of metatherian sites for each subepoch in which genera are present. For example, a bar in only the $0.0-0.2$ section depicts that all taxa appear in $20 \%$ or less of the fossil sites for that subepoch. Pie charts display in black the proportion of singleton occurrences that do not come from prolific sites in each subepoch. 
frequency target than the early and middle Miocene, increasing the number of genera sampled and creating a curve that is markedly different from that produced by the rarefaction analysis. As demonstrated above, the results of rarefaction are more affected by such frequency distributions than SQS results.

A further feature of the metatherian fossil record is the geographic clustering of "prolific sites" through time (Supplementary Data). When applied to the subepoch-level data, our method identified an uneven spread of "prolific sites." On a global scale, such sites are most numerous in the early Miocene by far (six sites), whereas the late Early Cretaceous, early Late Cretaceous, late Eocene, Oligocene, and Pliocene have only one or none at all. Moreover, the regional (i.e., by continent) occurrence of prolific sites displays little overlap within time bins: for example, time bins that contain a high number of prolific North American sites tend to be different from those containing a high number of prolific South American or Australian sites. Thus, the distribution of prolific sites is highly heterogeneous both temporally and spatially. Given the nature of the available data, it is likely that SQS (especially the version used here, with its modified treatment of Lagerstätte-like localities) will provide a more accurate reconstruction of metatherian diversity patterns than will classic rarefaction (although we note that our data do not allow us to set the target sampling level in SQS as high as that recommended by Alroy [2010]). For this reason, the following discussion will be based predominantly on the results of SQS.

\section{Metatherian Paleodiversity Patterns}

Early Cretaceous.--It has been proposed that metatherians had diverged from eutherians by the Oxfordian (160 Ma, based on the earliest eutherian fossils and resulting ghost ranges for metatherians [Luo et al. 2011; Williamson et al. 2014]). However, the Jurassic eutherian upon which this view is based has been placed outside of Theria in a recent phylogenetic analysis (Krause et al. 2014). The earliest confirmed metatherian material occurs in the Early Cretaceous of Asia-Sinodelphys szalayi, an exceptionally well-preserved fossil from the Barremian (Luo et al. 2003). This genus is generally regarded as the sister taxon to all other metatherians (Luo et al. 2003, 2011; Vullo et al. 2009; Williamson et al. 2014). Aside from Sinodelphys, the Early Cretaceous record of Metatheria is extremely patchy, consisting only of jaws and teeth from North America (e.g., Cifelli et al. 1998), including remains assignable to Deltatheroida (Kielan-Jaworowska and Cifelli 2001; Davis et al. 2008). This record may reflect genuine low diversity and abundance of the group during its initial radiation.

In the late Early Cretaceous, global climates were experiencing warm conditions, probably driven by high $\mathrm{CO}_{2}$ levels caused by active tectonism (Black et al. 2012; Tennant et al. 2017, and references therein). Mammaliaform diversity is believed to have generally increased from the Barremian to the Campanian (Wilson et al. 2012; Newham et al. 2014), perhaps reflecting radiations of insectivores and nectivores in association with the diversification of angiosperms (Black et al. 2012). Whether or not metatherians were affected by these events is difficult to judge with so little evidence available at present. However, Grossnickle and Newham (2016) noted that the disparity of metatherians and multituberculates (based on tooth shape and complexity) increased during the Late Cretaceous, which is in agreement with diversity patterns estimated here, and suggested that this disparity reflected the availability of frugivorous and omnivorous niches resulting from the growing ecological dominance of angiosperms.

Late Cretaceous.-The Late Cretaceous provides a much more abundant fossil record across all northern continents, with metatherian taxa belonging to either the Deltatheroida or Marsupialiformes (Williamson et al. 2014, and references therein). Deltatheroidans are particularly well known in Asia, where they were apparently more abundant than marsupialiforms (Averianov et al. 2010; Williamson et al. 2014). Deltatheroidans and several marsupialiform lineages (e.g., Stagodontidae, Pediomyidae, and basal Herpetotheriidae) are also present in the Late Cretaceous of North America (Case et al. 2004; Williamson et al. 2012, 2014). 
Both the rarefaction and SQS global curves estimate relatively low levels of generic diversity in the early part of the Late Cretaceous (Fig. 2A,B). In North America, however, the rarefaction curve displays a peak in the later part of the Late Cretaceous compared with earlier time bins (Fig. 3A). This latest Cretaceous regional pattern agrees with our raw diversity estimate (Fig. 1) and that of Williamson et al. (2014), who found peak diversity of 29 metatherian species in the Campanian. This result is consistent with the previous consensus (again based on raw taxic estimates) that a substantial metatherian radiation occurred in North America at this time (Cifelli and Davis 2003; Luo et al. 2003; Cifelli 2004), perhaps peaking in the Campanian and declining in the Maastrichtian (Kielan-Jaworowska et al. 2004). However, this scenario is contradicted by the SQS curve (Fig. 3B), which indicates that metatherian diversity plateaued between the early Late Cretaceous and late Late Cretaceous. We therefore suggest that the latest Cretaceous peak in North American metatherian raw diversity is largely an artifact of relatively good sampling, which has not been fully corrected by classic rarefaction. Other authors have previously noted the high quality of the metatherian latest Cretaceous North American fossil record compared with those of most other continental regions and time periods (e.g., Cifelli et al. 2014; Williamson et al. 2014). Moreover, this view is supported here by the observations that the latest Late Cretaceous subepoch includes: (1) a very high number of prolific sites in North America (10), compared with other region/time-bin combinations; and (2) an extremely high Good's $U$ value (0.99) in North America (Supplementary Data). This interpretation of unusually good fossil-record sampling in the latest Cretaceous is also relevant to assessments of the impact of the $\mathrm{K} / \mathrm{Pg}$ mass extinction on metatherians, discussed further below.

Paleocene.-The Paleocene includes the aftermath of the end-Cretaceous $(\mathrm{K} / \mathrm{Pg})$ mass extinction that resulted in the loss of $53-64 \%$ of terrestrial vertebrate species (Archibald 1996; Archibald and Bryant 1990) and 60\% of all animal species (Schulte et al. 2010). A recent study further suggested that extinction rates for North American mammals were markedly higher, around 93\% (Longrich et al. 2016). Previous studies, based on raw diversity counts, have concluded that metatherians underwent a severe and relatively sudden extinction at the end of the Cretaceous, resulting in a marked drop in diversity (e.g., Archibald 1983, 1996; Williamson et al. 2012), perhaps presaged by a small decline in raw species diversity (Wilson 2013; Williamson et al. 2014) and disparity (Grossnickle and Polly 2013) from the Campanian to the Maastrichtian. Mammalian community turnover has been documented in North American sites with sufficient continuous strata. For example, Hooker (2000) reported that, in Montana, $79 \%$ of Cretaceous mammals are replaced by novel forms in the Paleogene. With regard to Metatheria, stagodontid and pediomyid marsupialiforms do not cross the $\mathrm{K} / \mathrm{Pg}$ boundary, whereas the Glasbius + Roberthoffstetteria lineage and herpetotheriids apparently survived into the early Cenozoic (Horovitz et al. 2009; Williamson et al. 2012, 2014). Williamson et al. (2014) noted that raw species-level metatherian diversity only declined from 25 species in the Maastritchian to 23 in the Paleocene, but this "global" pattern obscures the fact the North American species' numbers decline markedly (by $66 \%$ to 8 species, with $100 \%$ turnover of genera), whereas known South American genera rise from 0 in the latest Cretaceous to 17 in the Paleocene (Table 1).

A significant extinction among metatherians at the $\mathrm{K} / \mathrm{Pg}$ boundary is also supported by recent studies that have examined mammalian or therian diversity and disparity using sampling-correction approaches. (Wilson 2013, 2014; Grossnickle and Newham 2016; Longrich et al. 2016). Wilson $(2013,2014)$ found evidence for a $91 \%$ extinction of metatherian taxa in North America, based on a detailed study of localities in northeast Montana and the application of rarefaction. Similarly, Longrich et al. (2016) estimated that North American mammalian diversity decreased by approximately $93 \%$ and $84 \%$ at the species and generic levels, respectively, including a 100\% turnover of metatherians at the $\mathrm{K} / \mathrm{Pg}$ boundary. Grossnickle and Newham (2016) found that 
both residual diversity estimates and SQS supported a significant drop in global therian diversity and disparity during the mass extinction. The extinction of mammalian taxa appears to have been selective, with metatherians losing more taxa and taking longer to recover than eutherians or multituberculates in North America (Longrich et al. 2016), and specialist forms were particularly hard hit (Grossnickle and Newham 2016).

A sharp decrease in diversity at or near the $\mathrm{K} / \mathrm{Pg}$ boundary is observed in our raw taxic diversity estimate for Europe, North America, and Asia (Fig. 1). In the rarefaction curves for North America and the global data set, there is a marked decrease in diversity in the Paleocene relative to the latest Cretaceous (Figs. 2A and 3A). SQS curves support a drop in diversity in North America (Fig. 3B), but these analyses indicate that global metatherian diversity was relatively high in the Paleocene (Fig. 2B). Thus, the raw taxic data and both our classic rarefaction and SQS results all support a major decrease in metatherian diversity in North America during the Cretaceous-Paleocene transition-a result that is consistent with the conclusions of the previous studies outlined earlier (e.g., Horovitz et al. 2009; Wilson 2013, 2014; Longrich et al. 2016). It seems, however, that the North American pattern cannot be simply extrapolated to the global scale. Although our rarefaction results (Fig. 2A) support a decrease in metatherian diversity in the Paleocene relative to the latest Cretaceous, the putatively more accurate SQS global curve (Fig. 2B) indicates a marked increase. Taken at face value, this pattern could be interpreted as indicating that metatherians were adversely affected by the $\mathrm{K} / \mathrm{Pg}$ mass extinction in the predominant Late Cretaceous range, North America, but rebounded quickly in new territory, particularly South America. However, the paucity of the non-North American Late Cretaceous fossil record of metatherians, coupled with the severe limitations on the temporal resolution of the ages of Paleocene taxa in many regions, warrants caution in these interpretations. First, the metatherian fossil records of Europe and Asia are so sparse that they cannot be subjected to rarefaction or SQS analysis. However, aside from Gurbanodelta, no
Paleocene Asian metatherians are known, despite their relative abundance and diversity in the latest Cretaceous, and it is thus conceivable that they were largely extirpated in this region during the $\mathrm{K} / \mathrm{Pg}$ mass extinction. Second, studies such as those carried out by Wilson (2013, 2014) and Longrich et al. (2016) focused on the 1-2 Myr on either side of the $\mathrm{K} / \mathrm{Pg}$ boundary, whereas our results compare diversity in the whole of the latest Cretaceous (Campanian-Maastrichtian, 17 Myr) and Paleocene ( $11 \mathrm{Myr})$. Although our data set has the advantage of providing global and regional sampling-corrected diversity estimates, it inevitably lacks the fine-scale temporal resolution achieved by these other analyses. Thus, our global Paleocene rise in diversity might obscure a more complex pattern in which metatherians underwent a major global extinction at the $\mathrm{K} / \mathrm{Pg}$ boundary, had suppressed diversity in the immediate aftermath of the mass extinction, but then recovered later in the Paleocene in regions other than North America and Asia (especially South America).

The oldest possible members of the crown group Marsupialia occur in the Paleocene (Goin et al. 2009; Horovitz et al. 2009; O'Leary et al. 2013; but see Beck 2012), perhaps reflecting their initial radiation in the wake of the K/ $\mathrm{Pg}$ mass extinction, although some estimates place the origin of Marsupialia in the latest Cretaceous (Williamson et al. 2014), similar to recent estimates for the origin of Placentalia (Wible et al. 2007; Meredith et al. 2011; dos Reis et al. 2012, 2014; Halliday et al. 2017; but see O'Leary et al. 2013). These findings suggest that Metatheria responded in the aftermath of the end-Cretaceous mass extinction in a manner similar to placental mammals: that is, experiencing an "explosive" and potentially adaptive radiation following the demise of the nonavian dinosaurs (Alroy 1999; dos Reis et al. 2012; Goswami 2012; O'Leary et al. 2013; Slater 2013; Halliday and Goswami 2016; Halliday et al. 2016). Unlike eutherians, however, the post-K/Pg metatherian radiation was apparently more geographically restricted, focused on the Southern Hemisphere. These ideas could be tested further by estimates of origination and extinction rates; however, the lack of new genera appearing in both the late 
Late Cretaceous and early Eocene means that calculation of such rates for the Paleocene is currently not possible (Table 2).

It has been suggested that high metatherian diversity in the Paleocene of South America might be due to an earlier arrival than that of eutherians (de Muizon and Cifelli 2001; Ortiz-Jaureguizar and Pascual 2007; Pascual and Ortiz-Jaureguizar 2007). However, there are many eutherians known from the early Paleocene of South America, in the same beds as the earliest metatherians (de Muizon and Cifelli 2000), and both of these clades are absent from Cretaceous beds of that continent. South American Cretaceous mammals include representatives of triconodonts and symmetrodonts (although see Gaetano et al. 2013) and "dryolestoids" and gondwanatheres (de la Fuente et al. 2007), with only "dryolestoids" and gondwanatheres, surviving to the Paleocene. It has often been suggested that metatherians were absent from Gondwanan continents during the Cretaceous and only dispersed into South America (and from there to other parts of Gondwana) during the Paleogene (Clemens 1968; Rage 1981, 1986), but it is also conceivable that this apparent paleobiogeographic pattern is an artifact of poor Southern Hemisphere sampling (Rana and Wilson 2003; Williamson et al. 2014). Metatherians probably arrived in South America from North America via the Greater Antilles or Aves Ridge, a volcanic arc (Iturralde-Vinent and MacPhee 1999; Pough et al. 2004; Hedges 2006) that was subareally exposed between the Campanian and Eocene. Owing to continual fluctuations in tectonism, magmatic activity, and sea level, this created an intermittent land connection between North and South America (Gayet et al. 1992; Case et al. 2004; Lowen et al. 2013; Wilf et al. 2013: though see Ezcurra and Agnolin 2012 for a contrary view).

Paleobotanical evidence suggests that the early Paleocene of South America was dominated by tropical and subtropical forests, as well as mangroves, swamp forest, montaine rain forest, and savanna-sclerophyllous forest, with temperate and mixed forest in the far south (Ortiz-Jaureguizar and Cladera 2006). This high diversity of arboreal habitats, which also persisted into the late Paleocene with the exception of the mangroves (Ortiz-Jaureguizar and Cladera 2006), might also have played a key role in the evolution of high metatherian diversity in clades dominated by arboreal taxa.

Eocene.-Metatherians first appear in the Antarctic and Australian fossil records in the early Eocene (e.g., Blake and Aronson 1998; Beck 2015). European metatherians occur in each of the four Eocene stages, yet only four genera are known: Amphiperatherium, Peratherium, Armintodelphys, and Peradectes. Asiadidelphis and Indodelphis are the only two genera known from the Asian Eocene. Given that Indodelphis comes from India (which collided with Asia during the latest Paleocene/earliest Eocene [Seton et al. 2012; $\mathrm{Hu}$ et al. 2016]), it is not certain whether this form represents an immigrant into India from Laurasia or a remnant of a Gondwanan fauna. Consequently, while it is clear that metatherians were widespread at this time, much of the information on their Eocene diversity is based on a relatively rich record in North and South America and a very scant record elsewhere. According to our results, global and South American metatherian diversity underwent a moderate rise during the early Eocene (Figs. 2B and 4B), yet suffered a slight decline in North America (Fig. 3). In the late Eocene, metatherians were still present in Europe and Asia; however, there is no record in Australia because of a lack of fossiliferous rock at this time (Fig. 6). At the global scale and in South America, metatherian diversity dropped in the late Eocene (Figs. 2B and 3), yet diversity rose in North America (Fig. 3).

Lower taxonomic diversity of mammals in the early Eocene of North America coincides with a loss of habitat heterogeneity caused by tectonics, climate and other related environmental factors (Janis 1993). The PaleoceneEocene thermal maximum (PETM) punctuated a warming trend that began in the late Paleocene and persisted through the Eocene (Shellito and Sloan 2006; Huyghe et al. 2015). Eustatic sea level was high, and sea water temperatures were elevated in the early Eocene (Haq et al. 1987; Zachos et al. 2001). Global warming at this time has been linked to the release of methane from continental shelf hydrates or 
from compressed sediments in the Gulf of Alaska, and/or $\mathrm{CO}_{2}$ linked to the North Atlantic Volcanic Province (Shellito and Sloan 2006, and references therein), with several recent studies favoring a key role for the latter factor (e.g., Bowen et al. 2015). Latitudinal thermal gradients were at their shallowest for the past 55 Myr (Moran et al. 2006), and deepocean circulation shifted, moving warm saltwater to higher latitudes (Rea et al. 1990).

As a consequence of these environmental changes, the early Eocene witnessed the greatest ever extent of tropical and subtropical forests (related to a poleward expansion of warm-adapted floras [Wing et al. 2004]), which in turn resulted in the most homogeneous biotas of the whole Cenozoic across northern continents (Woodburne 2004), although little is known about the floras of eastern Asia at this time (Shellito and Sloan 2006). Tropical forest is believed to have extended as far as $58^{\circ} \mathrm{N}$ and $47^{\circ} \mathrm{S}$ (Morley 2000; Jaramillo 2002; Mehrotra 2003; Shellito and Sloan 2006), with temperate mixed forest at higher latitudes (e.g., the Antarctic Peninsula (Hunt and Poole 2003) and in North America (Wing 1998; Wolfe and Dilcher 1999; Graham 2000). However, unlike in North America, South American metatherians were clearly thriving in this environment (Fig. 4), continuing the phase of major radiations on this continent that began in the Paleocene.

After the PETM, global temperatures peaked again in the middle Eocene, followed by a cooling and drying trend through the late Eocene (Janis 1993; Bohaty and Zachos 2003; Shellito and Sloan 2006; Jovane et al. 2007; Ivany et al. 2008; Villa et al. 2008; Bohaty et al. 2009; Huyghe et al. 2015). As temperatures cooled, tropical vegetation was replaced in northern latitudes by more temperate forest (with evidence of sclerophyllous plants in North America and Patagonia), although tropical forests still remained in equatorial regions (e.g., Kohn et al. 2015). The late Eocene also experienced an increase in seasonality in plant growth and the opening up of habitats as areas became less forested, as indicated by the increasing cursoriality seen in the ungulate fossil record (Janis 1993). Although North American metatherian diversity increased at this time (Fig. 3B), South American diversity declined, perhaps due to the arrival (from Africa) of caviomorph rodents and platyrrhine primates, which appear in the South American fossil record at $41 \mathrm{Ma}$ (Antoine et al. 2012) and $39 \mathrm{Ma}$ (Bond et al. 2015), respectively.

Oligocene.-Metatherian diversity in the Oligocene, despite declining from late Eocene levels in both North and South America (Figs. 3 and 4), rose "globally" (Fig. 2), largely because of the marked increase in taxa in the Australian (late) Oligocene record (Fig. 5). In Asia, only two genera, Asiadidelphis and Junggaroperadectes, are known. In addition, the only undisputed African metatherian is known from the Oligocene (Simons and Bown 1984).

By the beginning of the Oligocene, perhaps as a result of the habitat diversification of the late Eocene, North American eutherian mammals had radiated into specialized ecological groups. Lagomorphs and new rodent families had appeared, carnivorans had become more specialized to a variety of niches, and artiodactyl groups ranging from omnivores (pigs) to specialist folivores (camels and ruminants) were also present in North America (Janis 1993). It was perhaps through competition or predation by eutherians that North American metatherian diversity fell (Fig. 3B). However, the concept of "competitive displacement" of one group by another has been criticized by a number of studies, and many workers prefer models involving opportunistic replacement (e.g., Benton 2009, and references therein; Sanchez-Villagra 2013). Additionally, this pattern might reflect a failure of the metatherian groups in North America to adapt suitably and quickly enough to the changing habitat space. For example, declining global temperatures may not have been as tolerable to metatherians due to their lower BMR (Goin et al. 2016).

The substantially decreased temperatures at the Eocene/Oligocene boundary (EOB), followed by cooler temperatures throughout the Oligocene (Zachos et al. 2001), probably exerted strong environmental pressures on taxa living in southern South America. In general, South American Oligocene mammal communities were dominated by eutherian grazers such as notoungulates (OrtizJaureguizar and Cladera 2006). The dominant 
environment was that of woodland savanna with low annual rainfall, although the acquisition of high crowned teeth by many placental notoungulate families suggests wide-ranging temperate grasslands by the late Oligocene (Patterson and Pascual 1972). Given the appearance of new and varied scansorial and insectivorous-frugivorous metatherians in the South American Oligocene, such as the Paleothentidae and Abderitidae (Marshall 1980; Ortiz-Jaureguizar 2003; Abello 2013), borhyaenids, and the ricochetal argyrolagids (Goin et al. 2016), it is perhaps surprising that metatherians are estimated to have declined in diversity in this region at this time (Fig. 4). However, the Oligocene was a period of significant faunal turnover (Janis 1993), and although many new taxa occupying varied niches appeared, other South American forms such as the Polydolopidae and Groeberidae disappeared (Goin et al. 2016; Supplementary Data). This turnover is reflected in our estimate that metatherian extinction rates peaked during the Oligocene (Table 2).

During the Oligocene, Australia experienced "icehouse" conditions as a result of its severance from Antarctica and the oceanic circulation patterns that ensued (McGowran and Hill 2015, and references therein). Forests were less diverse than those of the early Eocene (Black et al. 2012) and experienced greater seasonality and lower rainfall. Late Oligocene Australian metatherians are known from several fossil sites in central and northern Australia; those at Riversleigh have been suggested to represent open-forest habitats (Travouillon et al. 2009). Perhaps the most important environmental feature at this time was the absence of terrestrial eutherians from the continent. Although there is a contentious terrestrial placental from the early Eocene Tingamarra Fauna of southeast Queensland, Australia (Godthelp et al. 1992), it apparently did not persist, and the continental isolation that followed the late Eocene separation likely limited further invasions. As a result, despite the globally changing biotic environment, Australian metatherians were able to diversify substantially to fill these new ecological niches with specialized insectivores, carnivores, and herbivores (Black et al. 2012) (Fig. 5B), unlike in North and South America (Figs. 3 and 4).
Miocene.-Globally, metatherian diversity experienced a rise from the Oligocene to its maximum in the early Miocene, a drop in the middle and late Miocene, and then a rise in the Pliocene (Fig. 2). These sampling-corrected reconstructions agree with the raw diversity curve (Fig. 1).

The Miocene shows the last of the Laurasian metatherians until the northward dispersal of opossums into North America (represented by Didelphis virginiana today) from South America during the great American biotic interchange (GABI) in the Quaternary (see reviews in Bacon et al. [2015], Montes et al. [2015], and Woodburne [2010] for a discussion of the complex history of the GABI). The Miocene record for North American metatherians comprises only a single genus, Herpetotherium, recovered from six early Miocene fossil sites (e.g., Whistler and Lander 2003). In Europe, a few metatherians have also been recorded from the early Miocene (e.g., Legendre 1982; Ziegler 1990), but none are known after this time. In South America, metatherian diversity fell in the middle Miocene and plateaued to the late Miocene (Fig. 4). No taxa are known from the Miocene of Antarctica, although access to outcrop is of course limited by ice cover. In Australia, diversity initially increased from the Oligocene but fell in the middle and late Miocene (Fig. 5). Thus, the global pattern of metatherian diversity in the Miocene largely mirrors that of Australia.

The early Miocene was a time of greenhouse conditions with rising sea levels and warm humid climate as a result of the melting of polar ice caps (Zachos et al. 2001). In South America, explosive volcanism in the latest early Miocene was followed by the uplift of the Andes in the middle Miocene (Uliana and Biddle 1988; Echeverri et al. 2015). In the early Miocene, South American habitats displayed a balance between grasslands and woodlands, with the persistence of tropical forests in Patagonia, and grasses and shrubs being more widely distributed than previously (Ortiz-Jaureguizar and Cladera 2006). Generally, at this time, subtropical forest was declining, and montane forest was increasing in dominance (Quattrocchio et al. 2003). It was also in the early to middle Miocene that the first 
evidence of steppe-like habitats, in a relatively dry climate, is known, although some recent work has suggested that desertification of Patagonia did not occur until the late Miocene $(\sim 10$ Ma) (Palazzesi and Barreda 2012; Palazzesi et al. 2014). At this time, grazers dominated the South American fauna, followed in abundance by mixed feeders, frugivores, and browsers (Ortiz-Jaureguizar and Cladera 2006).

The South American middle to late Miocene witnessed three successive Atlantic marine transgressions known as the Paranean Sea that later gave way to new habitats of widespread plains (the "Age of the Southern Plains") in the late Miocene (Ortiz-Jaureguizar and Cladera 2006). During this time, climate was cooler and more seasonal and environments more subdivided than in the early Miocene; this has been linked to ice cap formation in the eastern Arctic and the first evidence of glacial advance in the south (Pascual et al. 1996). The late Miocene of Patagonia was dominated by open and arid environments (Ortiz-Jaureguizar and Cladera 2006). It is at this time that certain taxa linked to subtropical woodlands, such as stegotheriine armadillos and paleothentid and aberitid marsupials, became rare or disappeared entirely.

In the early Miocene of Australia, there is evidence for widespread rain forest of the kind comparable to the mid-montane rain forests of New Guinea (Black et al. 2012). Conditions were drier and more seasonal in central Australia compared with northern and eastern parts of that continent, although wetter than they are at present (Martin 2006). Northward movement of the Australian plate, after its rifting from Antarctica, resulted in a collision with Southeast Asia in the middle Miocene and subsequent closure of the deep-sea circulation between Australia and Indonesia (Kennett 1977). This change in circulation is correlated with ice sheet expansion in eastern Antarctica, mentioned earlier, that resulted in even lower sea level, temperatures, and precipitation (Lawver and Gahagan 2003). Thus, Australia experienced the same shift in climate as South America and much of the rest of the world after the middle Miocene climatic optimum, as greenhouse conditions with peak rainfall and sea level gave way to cooler, drier conditions
(Black et al. 2012). This period of drying was exacerbated by mountain uplift in New Guinea and of the Eastern Dividing Range in Australia, both creating rain-shadow effects (Black et al. 2012). These abiotic factors inevitably influenced the biotic realm and led to the gradual replacement of central Australian rain forests by open forest and woodland, although rain forests remained on the continental margins (Black et al. 2012). The late Miocene of Australia saw even further cooling, and reduction and fragmentation of the rain forests (Zachos et al. 2001). Dry open woodlands were present in central Australia, and eucalyptus trees were abundant (Martin 1994). The diversity curves (Fig. 5) indicate that metatherian diversity decreased from the middle Miocene to the late Miocene, suggesting that they may have failed to adapt sufficiently to these drier and cooler woodland conditions.

Pliocene.-In the Pliocene, metatherians are mainly known from South America and Australia, with only a few taxa in Central America; thus, their paleobiogeographic distribution at this time was essentially identical to that which is observed today, excluding the North American Didelphis virginiana. Metatherian diversity declined from the late Miocene onward in South America (Fig. 4) but increased in the Pliocene in Australia (Fig. 5). Globally, the Pliocene witnessed a fluctuation in climate with expansion and contraction of Northern and Southern Hemisphere ice sheets (Zachos et al. 2001). The early Pliocene was characterized by global warming and marine transgression. This was followed by a major transition involving extensive arctic glaciation, global cooling, and increasing climatic instability (Shackleton et al. 1984; Kennett 1985; Shackleton 1995; Zhang et al. 2001; Lisiecki and Raymo 2007).

In South America, continuing uplift of the Andean Cordillera formed a barrier to humid winds from the Pacific and created a rain-shadow effect that increased aridity (Ortiz-Jaureguizar and Cladera 2006; La Roux 2012). Major glaciations dominated Patagonia (Mörner and Sylwan 1989; La Roux 2012) and probably contributed to reduced continental temperatures. As a result of these climatic events, habitats were dominated by grasslands, steppes, and shrublands in arid zones, 
with rain forest being restricted to small areas near the Brazilian coastline, montane forest occurring in north-central Argentina, Paraguay, and Bolivia, and cool moist temperate forest growing in southwest Patagonia (Dowsett et al. 1999; Ortiz-Jaureguizar and Cladera 2006). The negative impact of increasing aridity on metatherian diversity potentially reflects the correlation between lactation and rainy season in extant metatherians (e.g., McNab 1986, 2005, 2008; Krockenberger 2006). If metatherians were failing to lactate in dry seasons or arid conditions, this would have affected their rate of population growth and might explain their decline in South America during periods of increasing aridity.

The history of the Isthmus of Panama, and associated GABI, is now more complex than previously realized. It used to be thought that this region provided a land bridge for terrestrial dispersal between North and South America from around 5-3.5 Ma, whereas recent studies have proposed phases of biotic exchange at 20 and $6 \mathrm{Ma}$ (Bacon et al. 2015) and the emergence of a land connection approximately 15-13 Ma (Montes et al. 2015). Nevertheless, the Pliocene is associated with the beginning of high-volume immigration from North America (GABI), potentially related to climatic cooling that resulted in savannas suitable for dispersal of mammalian herbivores (Molnar 2008; Hoorn and Flantua 2015). GABI involved dispersal of carnivorans (including bears, dogs, and cats), rodents, and ungulates (such as camels, deer, tapirs, horses, and gomphothere proboscideans) to South America in the Pliocene (Flynn and Wyss 1998). Although there is little evidence for competitive replacement of sparassodonts by eutherian carnivores (Prevosti et al. 2013), the presence of these new placental taxa likely had a large effect on metatherian communities (see Jansa et al. [2014] for evidence of a didelphid extinction), perhaps through increased predation pressure and competition for resources. Moreover, it has been suggested that rodents, for example, filled similar niches to some metatherians (Pascual et al. 1996; Ortiz-Jaureguizar and Cladera 2006), potentially leading to competition among these small-bodied mammals in South America. However, see previous comments about competitive replacement. Thus, South American metatherian diversity might have decreased during the Miocene and Pliocene as a result of abiotic factors such as increasing aridity, opening up additional niches that could only be filled by the invading placental groups.

In Australia, the early Pliocene has been reconstructed as initially warm and wet before becoming increasingly arid again in the late Pliocene (Gallagher et al. 2003). There were considerable gradients in climate (and hence also vegetation) across Australia, which comprised wet sclerophyll forests in peripheral regions, rain forest near the coast, and drier forest farther inland (Hill 1992; McGowran et al. 2000; Martin 2006). The ecological diversity of marsupials reflected these habitats in the early Pliocene, where arboreal and browsing taxa were abundant. In the later Pliocene, rain forest persisted in southeast Australia. A shift to increased seasonality in rainfall is also indicated by the rise of herbaceous plants (Greenwood and Christophel 2005). The increasing dominance of arid shrubs and grasslands in the northwest of central Australia in the late Pliocene (Martin 2006) might explain the significant radiation of grazing marsupials (kangaroos and wombats) at this time. The appearance of "old endemic" murids in the Australian Pliocene might have impacted metatherians (such as the rodent-like ektopodontid possums) through competitive replacement (Black et al. 2012).

\section{Metatherian Fossil-Record Quality}

The classic rarefaction and SQS results demonstrate that it is possible to extract sampling-corrected paleodiversity estimates for metatherians at both global and regional scales. These results, however, frequently display differences from raw taxic diversity counts. Such discrepancies indicate that the metatherian fossil record is very patchy and that sampling biases distort the true diversity pattern for this group.

Our understanding of early metatherian diversity in Asia and Europe is poor. Cretaceous Asian metatherian fossils have a record punctuated by large gaps, such as that between 
the first recorded metatherian, Sinodelphys (Barremian, 129.4-125 Ma) and the next Asian fossil, Sulestes (Coniacian, 89.8-86.3 Ma) (Nessov 1985; Supplementary Data). There are no Asian metatherians from the Santonian (86.3-83.6 Ma); only two genera, Asiatherium (Trofimov and Szalay 1994) and Deltatheridium (Rougier et al. 1998) in the Campanian (83.6-72.1 Ma); and only the unnamed "Gurlin Tsav" skull (Kielan-Jaworowska and Nessov 1990) in the Maastrichtian. For this reason, hypotheses concerning an eastern or western dispersal route from Asia are difficult to test, as outlined by Vullo et al. (2009).

Metatherian fossils from Europe are known from the Cenomanian (100.5-93.9 Ma) and the Maastrichtian (72.1-66 Ma), but no record bridges these stages. This major gap in the fossil record might be the result of the rarity of screen-washing studies that are able to recover small fossil mammal teeth. Alternatively, metatherians might have been truly scarce or absent during this time.

We know very little of how metatherians fared during their bidirectional Antarctic dispersals between South America and Australia. The fossil record of Antarctica is greatly undersampled, owing to its current coverage in ice. Thus far, it has only yielded fossil metatherians of early Eocene age (Montes et al. 2013). This lack of data severely limits our understanding of the role of this landmass as a "bridge" between South America and Australia and the faunal exchanges and interactions that might have taken place.

The Australian record has yet to produce any metatherian fossils from the late Eocene, due to a paucity of fossiliferous rock. This deficit obscures our understanding of the initial diversification of Australian clades and their colonization of the continent that they still dominate. Future work must endeavor to fill these gaps in the record through exploration of potential fossil sites and increased sampling of those sites already known.

\section{Conclusions}

The quality of the metatherian fossil record varies extensively, both spatially and temporally. For example, fossil-record quality in North
America contrasts greatly with that of South America, and there are many gaps in regions and time bins because of poor collection effort or lack of fossiliferous rock. Accordingly, the raw metatherian fossil record is biased by varied sampling and preservation rates through time and hence does not provide a reliable picture of paleodiversity patterns. Application of appropriate sampling-correction techniques, however, yields information on metatherian diversity that is likely to be more accurate than a simple reading of the raw fossil record. Rarefaction, and especially SQS, handle the complex and patchy nature of the metatherian fossil record and ameliorate several likely sources of bias. Given the very heterogeneous sampling, classic rarefaction is likely to give less accurate estimates of diversity than SQS.

The evidence presented here suggests that metatherian diversity was relatively low globally during the Cretaceous. Apparent decreases in global raw taxic diversity in the Paleocene are, at least in part, artifacts of poor sampling. It seems that metatherians actually diversified considerably during the mid- and late Paleocene after a substantial extinction/ turnover event (which was perhaps particularly severe in Laurasia) close to the $\mathrm{K} / \mathrm{Pg}$ boundary. In particular, metatherian diversity increased greatly in South America during the Paleocene, possibly reflecting the availability of varied arboreal habitats and/or a lack of competition from eutherians. Thus, Metatheria (especially Marsupalia) radiated after the K/ $\mathrm{Pg}$ extinction in a manner resembling the diversification of contemporary placental mammals, albeit on a smaller and probably more geographically restricted scale. After the early Eocene peak, global metatherian diversity dipped until their extensive radiation within Australia. Thus, the Cenozoic diversity history of metatherians has a strongly regionalized aspect, with the clade declining markedly in Europe (and also North America after a peak in the Eocene), so that it is absent from Laurasia from the middle Miocene onward (with the exception of Didelphis which dispersed into North America in the last 1 Myr [Woodburne 2010]). In the Southern Hemisphere, while South American diversity declined from an early Eocene peak, diversification of Australian forms 
in the Miocene-Pliocene more than compensated for these losses and those in Laurasia. This high Australian diversity accounts for the maximum peak in global diversity during the early Miocene.

Fluctuations in metatherian diversity potentially correspond with environmental factors such as climate change, habitat heterogeneity and fragmentation, and continental connectivity. Although there are exceptions (such as the Miocene-Pliocene of Australia), it seems that metatherian diversity tended to rise when arboreal habitats were varied and climates were warmer and more mesic, but decreased when more arid conditions created open grasslands, steppes, and deserts. The different styles of lactation displayed by metatherians and placentals might have played a key role in allowing the latter to exploit these more arid environments, or warmer temperatures might have been more optimal for metatherian low BMR (Goin et al. 2016, and references within). Where environments provided opportunities for the diversification of placental mammals, metatherians usually did not follow suit. While the large-scale patterns in metatherian diversity are unlikely to have been driven directly by competition with placental mammals, it is conceivable that the absence or rarity of the latter in the Paleocene of South America and Miocene-Pliocene of Australia meant that metatherians found it easier to respond to changing habitats by radiating into new niches without facing incumbent placentals. Moreover, the developmental and/or physiological constraints potentially limited the ecomorphological evolution in Metatheria, contributing to their past and present patterns of biodiversity.

\section{Acknowledgments}

We thank Gavin Simpson for his assistance with the creation of the initial version of the SQS R code. Roger Benson and Philip Mannion provided valuable discussion concerning methodologies used to produce samplingcorrected paleodiversity estimates. We also thank Steve Brusatte and Robin Beck for helpful reviews. We are grateful to the library staff at The Natural History Museum, London, for assistance with locating many references in their care. C.V.B. was supported by Natural Environment Research Council doctoral training grant NE/H525197/1.

\section{Literature Cited}

Abello, M. A. 2013. Analysis of dental homologies and phylogeny of Paucituberculata (Mammalia: Marsupialia). Biological Journal of the Linnean Society 109:441-465.

Alroy, J. 1999. The fossil record of North American mammals: evidence for a Paleocene evolutionary radiation. Systematic Biology 48:107-118.

- 2008. Dynamics of origination and extinction in the marine fossil record. Proceedings of the National Academy of Sciences USA 105:11536-11542.

—. 2010. Geographical, environmental and intrinsic biotic controls on Phanerozoic marine diversification. Palaeontology 53:1211-1235.

- 2015. Current extinction rates of reptiles and amphibians. Proceedings of the National Academy of Sciences USA 112:13003-13008.

Alroy, J., C. R. Marshall, R. K. Bambach, K. Bezusko, M. Foote, F. T. Fürsich, T. A. Hansen, S. M. Holland, L. C. Ivany, D. Jablonski, D. K. Jacobs, D. C. Jones, M. A. Kosnik, S. Lidgard, S. Low, A. I. Miller, P. M. Novack-Gottshall, T. D. Olszewski, M. E. Patzkowsky, D. M. Raup, K. Roy, J. J. Sepkoski, M. G. Sommers, P. J. Wagner, and A. Webber. 2001. Effects of sampling standardization on estimates of Phanerozoic marine diversification. Proceedings of the National Academy of Sciences USA 98:6261-6266.

Alroy, J., M. Aberhan, D. J. Bottjer, M. Foote, F. T. Fürsich, P. J. Harries, A. J. Hendy, S. M. Holland, L. C. Ivany, W. Kiessling, and M. A. Kosnik. 2008. Phanerozoic trends in the global diversity of marine invertebrates. Science 321:97-100.

Antoine, P. O., L. Marivaux, D. A. Croft, G. Billet, M. Ganerød, C. Jaramillo, T. Martin, M. J. Orliac, J. Tejada, A. J. Altamirano, and F. Duranthon. 2012. Middle Eocene rodents from Peruvian Amazonia reveal the pattern and timing of caviomorph origins and biogeography. Proceedings of the Royal Society of Biology 279:1319-1326.

Archer, M., S. Hand, and H. Godthelp. 1988. A new order of Tertiary zalambdodont marsupials. Science 239:1528-1531.

Archibald, J. D. 1983. Structure of the K-T mammal radiation in North America: speculations on turnover rates and trophic structure. Acta Palaeontologica Polonica 28:7-17.

- 1996. Dinosaur extinction and the end of an era. Columbia University Press, New York.

Archibald, J. D., and L. J. Bryant. 1990. Differential Cretaceous Tertiary extinctions of non-marine vertebrates-evidence from northeastern Montana. Geological Society of America Special Paper 247:549-562.

Averianov, A. O., J. D. Archibald, and E. G. Ekdale. 2010. New material of the Late Cretaceous Deltatheroidan mammal Sulestes from Uzbekistan and phylogenetic reassessment of the metatherian-eutherian dichotomy. Journal of Systematic Palaeontology 8:301-330.

Bacon, C. D., D. Silvestro, C. Jaramillo, B. T. Smith, P. Chakrabarty, and A. Antonelli. 2015. Biological evidence supports an early and complex emergence of the Isthmus of Panama. Proceedings of the National Academy of Sciences USA 112:6110-6115.

Badgley, C. 2003. The multiple scales of biodiversity. Paleobiology 29:11-13.

Beck, R. M. D. 2009. Was the Oligo-Miocene Australian metatherian Yalkaparidon a "mammalian woodpecker"? Biological Journal of the Linnean Society 97:1-17.

_ 2012. An "ameridelphian" marsupial from the early Eocene of Australia supports a complex model of Southern Hemisphere marsupial biogeography. Naturwissenschaften 99:715-729. 
- 2015. A peculiar faunivorous metatherian from the early Eocene of Australia. Acta Palaeontologica Polonica 60:123-129.

Bennett, C. V., and A. Goswami. 2013. Statistical support for the hypothesis of developmental constraint in marsupial skull evolution. BMC Biology 11:52.

Benson, R. B. J., and R. J. Butler. 2011. Uncovering the diversification history of marine tetrapods: ecology influences the effect of geological sampling biases. Geological Society of London Special Publication 358:191-207.

Benson, R. B. J., R. J. Butler, J. Lindgren, and A. S. Smith. 2010. Mesozoic marine tetrapod diversity: mass extinctions and temporal heterogeneity in geological megabiases affecting vertebrates. Proceedings of the Royal Society of London B 277:829-834.

Benton, M. J. 2009. The Red Queen and court jester: species diversity and the role of biotic and abiotic factors through time. Science 323:728.

Benton, M. J., A. M. Dunhill, G. T. Lloyd, and F. G. Marx. 2011. Assessing the quality of the fossil record: insights from vertebrates. Geological Society of London, Special Publication 358:63-94.

Black, K. H., M. Archer, S. J. Hand, and H. Godthelp. 2012. The rise of Australian marsupials: a synopsis of biostratigraphic, phylogenetic, palaeoecologic and palaeobiogeographic understanding. Pp 983-1078 in J. A. Talent, ed. Earth and life. Springer, Dordrecht, Netherlands.

Black, K. H., G. J. Price, M. Archer, and S. J. Hand. 2014. Bearing up well? Understanding the past, present and future of Australia's koalas. Gondwana Research 25:1186-1201.

Blake, D. B., and R. B. Aronson. 1998. Eocene stelleroids (Echinodermata) at Seymour Island, Antarctic Peninsula. Journal of Paleontology 72:339-353.

Bohaty, S. M., and J. C. Zachos. 2003. Significant Southern Ocean warming event in the late middle Eocene. Geology 31:1017-1020.

Bohaty, S. M., J. C. Zachos, F. Florindo, and M. L. Delaney. 2009. Coupled greenhouse warming and deep-sea acidification in the middle Eocene. Paleoceanography 24:PA2207.

Bond, M., M. F. Tejedor, K. E. Campbell Jr, L. Chornogubsky, N. Novo, and F. Goin. 2015. Eocene primates of South America and the African origins of New World monkeys. Nature 520:538-541.

Bowen, G. J., B. J. Maibauer, M. J. Kraus, U. Rohl, T. Westerhold, A. Steimke, P. D. Gingerich, S. L. Wing, and W. C. Clyde. 2015. Two massive, rapid releases of carbon during the onset of the Palaeocene-Eocene thermal maximum. Nature Geoscience 8: 44-47.

Brusatte, S., R. J. Butler, P. M. Barrett, M. T. Carrano, D. C. Evans, G. T. Lloyd, P. D. Mannion, M. A. Norell, D. J. Pepp, P. Upchurch, and T. E. Williamson. 2015. The extinction of the dinosaurs. Biological Reviews 90:628-642.

Bush, A. M., M. J. Markey, and C. R. Marshall. 2004. Removing bias from diversity curves: the effects of spatially organized biodiversity on sampling-standardization. Paleobiology 30: 666-686.

Butler, R. J., P. M. Barrett, S. Nowbath, and P. Upchurch. 2009. Estimating the effects of sampling biases on pterosaur diversity patterns: implications for hypotheses of bird/pterosaur competitive replacement. Paleobiology 35:432-446.

Butler, R. J., R. B. J. Benson, M. T. Carrano, P. D. Mannnion, and P. Upchurch. 2011. Sea level, dinosaur diversity and sampling biases: investigating the "common cause" hypothesis in the terrestrial realm. Proceedings of the Royal Society of London B 278:1165-1170.

Case, J. A., F. J. Goin, and M .O. Woodburne. 2004. "South American" marsupials from the Late Cretaceous of North America and the origin of marsupial cohorts. Journal of Mammalian Evolution 11:223-255.

Cifelli, R. L. 2004. Chapter 5: Marsupial mammals from the Albian-Cenomanian (Early-Late Cretaceous) boundary, Utah. Bulletin of the American Museum of Natural History 285:62-79.
Cifelli, R. L., and B. M. Davis. 2003. Paleontology. Marsupial origins. Science 302:1899-1900.

Cifelli, R. L., J. R. Wible, and F. A. Jenkins. 1998. Triconodont mammals from the Cloverly Formation (Lower Cretaceous), Montana and Wyoming. Journal of Vertebrate Paleontology 18:237-241.

Cifelli, R. L., B. M. Davis, and B. Sames. 2014. Earliest Cretaceous mammals from the western United States. Acta Palaeontologica Polonica 59:31-52.

Clemens, W. A. 1968. Origin and early evolution of marsupials. Evolution 22:1-18.

Crampton, J. S., A. G. Beu, R. A. Cooper, C. M. Jones, B. Marshall, and P. A. Maxwell. 2003. Estimating the rock volume bias in paleobiodiversity studies. Science 301:358-360.

Davis, B. M., R. L. Cifelli, and Z. Kielan-Jaworowska. 2008. Earliest evidence of Deltatheroida (Mammalia: Metatheria) from the Early Cretaceous of North America. Pp. 3-24 in E. J. Sargis and M. Dagosto, eds. Mammalian evolutionary morphology: a tribute to Frederick S. Szalay. Springer, Dordrecht, Netherlands. de la Fuente, M. S., L. Salgado, A. Albino, A. M. Báez, J. F. Bonaparte, J. O. Calvo, L. M. Chiappe, L. S. Codorniú, R. A. Coria, Z. Gasparini, and B. J. González Riga. 2007. Tetrápodos continentales del Cretácico de la Argentina: una síntesis actualizada. In Asociación Paleontológica Argentina Publicación Especial 11(Ameghiniana 50 aniversario): 137-153. Buenos Aires, 25 November 2007.

de Muizon, C., and R. L. Cifelli. 2000. The "condylarths" (archaic Ungulata, Mammalia) from the early Palaeocene of Tiupampa (Bolivia): implications on the origin of the South American ungulates. Geodiversitas 22:47-150.

—. 2001. A new basal "didelphoid" (Marsupialia, Mammalia) from the early Paleocene of Tiupampa (Bolivia). Journal of Vertebrate Paleontology 21:87-97.

dos Reis, M., J. Inoue, M. Hasegawa, R. J. Asher, P. C. Donoghue, and Z. Yang. 2012. Phylogenomic datasets provide both precision and accuracy in estimating the timescale of placental mammal phylogeny. Proceedings of the Royal Society of London B 279:3491-3500.

dos Reis, M., P. C. J. Donoghue, and Z. Yang. 2014. Neither phylogenomic nor palaeontological data support a Palaeogene origin of placental mammals. Biology Letters 10:20131003.

Dowsett, H. J., J. A. Barron, R. Z. Poore, R. S. Thompson, T. M. Cronin, S. E. Ishman, and D. A. Willard. 1999 Middle Pliocene paleoenvironmental reconstruction: PRISM2. US Geological Survey Open File Report 99-535.

Echeverri, S., A. Cardona, A. Pardo, G. Monsalve, V. A. Valencia, C. Borrero, S. Rosero, and S. Lopez. 2015. Regional provenance from southwestern Colombia fore-arc and intra-arc basins: implications for Middle to Late Miocene orogeny in the Northern Andes. Terra Nova 27:356-363.

Ezcurra, M. D., and F. L. Agnolin. 2012. A new global palaeobiogeographical model for the late Mesozoic and early Tertiary. Systematic Biology 61:553-566.

Fastovsky, D. E., Y. Huang, J. Hsu, J. Martin-McNaughton, P. M. Sheehan, and D. B. Weishampel. 2004. Shape of Mesozoic dinosaur richness. Geology 32:877-880.

Flannery, T. F, W. D. Turnbull, T. H. V. Rich, and E. L. Lundelius. 1987. The phalangerids (Marsupialia: Phalangeridae) of the early Pliocene Hamilton Local Fauna, Southwestern Victoria. Pp. 537546 in M. Archer, ed. Possums and opossums: studies in evolution. Surrey Beatty and Sons and the Royal Zoological Society of New South Wales, Sydney.

Flynn, J. J., and A. Wyss. 1998. Recent advances in South American mammalian paleontology. Trends in Ecology and Evolution 13:449-54.

Foote, M. 2001. Inferring temporal patterns of preservation, origination, and extinction from taxonomic survivorship analysis. Paleobiology 27:602-630. 
Fröbisch, J. 2008. Global taxonomic diversity of anomodonts (Tetrapoda, Therapsida) and the terrestrial rock record across the Permian-Triassic boundary. PLoS ONE 3: p. e3733.

Gaetano, L. C., C. A. Marsicano, and G. W. Rougier. 2013. A revision of the putative Late Cretaceous triconodonts from South America. Cretaceous Research 46:90-100.

Gallagher, S. J., D. R. Greenwood, D. Taylor, A. J. Smith, M. W. Wallace, and G. R. Holdgate. 2003. The Pliocene climatic and environmental evolution of southeastern Australia: evidence from the marine and terrestrial realm. Palaeogeography, Palaeoclimatology, Palaeoecology 193:349-382.

Gayet, M., J. C. Rage, T. Sempere, and P. Y. Gagnier. 1992. Modalités des échanges de vertébrés continentaux entre l'Amérique du Nord et l'Amérique du Sud au Crétacé supérieur et au Paléocène. Bulletin de la Société Géologique de France 163:781-791.

Geoscience Australia and Australian Stratigraphy Commission. 2013. Australian Stratigraphic Units Database. http://www.ga. gov.au/products-services/data-applications/reference-databases/ stratigraphic-units.html, accessed 1 May 2013.

Godthelp, H., M. Archer, and R. Cifelli. 1992. Earliest known Australian Tertiary mammal fauna. Nature 356:514-516.

Goin, F. J., A. M. Candela, M. A. Abello, and E. V. Oliveira. 2009. Earliest South American paucituberculatans and their significance in the understanding of "pseudodiprotodont" marsupial radiations. Zoological Journal of the Linnean Society 155:867-884.

Goin, F. J., M. O. Woodburne, A. N. Zimicz, G. M. Martin, and L. Chornogubsky. 2016. A brief history of South American metatherians. Springer, Dordrecht, Netherlands.

- 2016. Paleobiology and adaptations of Paleogene metatherians. Pp. 185-208 in A brief history of South American metatherians. Springer, Dordrecht, Netherlands.

Good, I. J. 1953. The population frequencies of species and the estimation of population parameters. Biometrika 40:237-264.

Goswami, A. 2012. A dating success story: genomes and fossils converge on placental mammal origins. EvoDevo 3:18.

Goswami, A., M. Randau, P. D. Polly, V. Weisbecker, C. V. Bennett, L. Hautier, and M. R. Sánchez-Villagra. 2016. Do developmental constraints and high integration limit the evolution of the marsupial oral apparatus? Integrated Comparative Biology 56:404-415.

Graham, A. 2000. History of North American vegetation-Cretaceous (Maastrichtian)-Tertiary. Pp. 57-70 in F.o.N.A.E. Committee ed. Flora of North America north of Mexico. Oxford University Press, New York.

Greenwood, D., and D. Christophel. 2005. The origins and Tertiary history of Australian "tropical" rainforests. Pp. 336-373 in E. Bermingham, C. Dick, and C. Moritz, eds. Tropical rainforests: past, present, future. University of Chicago Press, Chicago.

Grossnickle, D. M., and E. Newham. 2016. Therian mammals experience an ecomorphological radiation during the Late Cretaceous and selective extinction at the K-Pg boundary. Proceedings of the Royal Society of London B 283:20160256.

Grossnickle, D. M., and P. D. Polly. 2013. Mammal disparity decreases during the Cretaceous angiosperm radiation. Proceedings of the Royal Society of London B 280 280:20132110.

Halliday, T. J. D., and A. Goswami. 2016. Eutherian morphological disparity across the end-Cretaceous mass extinction. Biological Journal of the Linnean Society 118:152-168.

Halliday, T. J. D., P. Upchurch, and A. Goswami. 2016. Eutherians experience elevated evolutionary rates in the immediate aftermath of the Cretaceous-Palaeogene mass extinction. Proceedings of the Royal Society of London B 283:20153026.

—. 2017. Resolving the relationship of Palaeocene placental mammals. Biological Reviews 92:521-550.

Haq, B. U., J. Hardenbol, and P. R. Vail. 1987. Chronology of fluctuating sea levels since the Triassic. Science 235:1156-1167.
Harrell, F. E., and C. Dupont. 2013. Hmisc: Harrell miscellaneous. R package, Version 3.10-1.1. http://CRAN.R-project.org/package $=$ Hmisc.

Hedges, S. B. 2006. Paleogeography of the Antilles and the origin of West Indian terrestrial vertebrates. Annals of the Missouri Botanical Garden 93:231-244.

Hill, R. 1992. Nothofagus: evolution from a southern perspective. Trends in Ecology and Evolution 7:190-194.

Hocknull, S. 2005. Additional specimens of Bohra (Marsupialia: Macropodidae) from the Pliocene of Queensland. Memoirs of the Queensland Museum 51:26.

Hooker, J. J. 2000. Palaeogene mammals: crises and ecological change. Pp. 333-349 in S. Culver and P. Rawson, eds. Biotic response to global change: the last 145 million years. Cambridge University Press, Cambridge.

Hoorn, C., and S. Flantua. 2015. An early start for the Panama land bridge. Science 348:186-187.

Horovitz, I., T. Martin, J. Bloch, S. Ladevèze, C. Kurz, and M. R. Sánchez-Villagra. 2009. Cranial anatomy of the earliest marsupials and the origin of opossums. PLoS ONE. doi: 10.1371/journal.pone.0008278.

Hu, X., E. Garzanti, J. Wang, W. Huang, W. An, and A. Webb. 2016. The timing of India-Asia collision onset-facts, theories, controversies. Earth Science Reviews 160:264-299.

Hunt, R., and I. Poole. 2003. Paleogene West Antarctic climate and vegetation history in light of new data from King George Island. In S. L. Wing, P. Gingerich, B. Schmitz, and E. Thomas, eds. Causes and consequences of globally warm climates in the early Paleogene. Geological Society of America Special Paper 369:395-412.

Huyghe, D., F. Lartaud, L. Emmanuel, D. Merle, and M. Renaud. 2015. Palaeogene climate evolution in the Paris Basin from oxygen stable isotope $(\delta 18 \mathrm{O})$ compositions of marine molluscs. Journal of the Geological Society 172:576-587.

Iturralde-Vinent, M., and R. D. E. MacPhee. 1999. Paleogeography of the Caribbean region: implications for Cenozoic biogeography. Bulletin of the American Museum of Natural History 238:1-95.

Ivany, L. C., K. C. Lohmann, F. Hasiuk, D. B. Blacke, A. Glass, R. B. Aronson, and R. M. Moody. 2008. Eocene climate record of a high southern latitude continental shelf: Seymour Island, Antarctica. Geological Society of America Bulletin 120:659-678.

Jablonski, D., K. Roy, J. W. Valentine, R. M. Price, and P. S. Anderson. 2003. The impact of the pull of the recent on the history of marine diversity. Science 360:1133-1135.

Janis, C. M. 1993. Tertiary mammal evolution in the context of changing climates, vegetation, and tectonic events. Annual Review of Ecology and Systematics 24:467-500.

Jansa, S. A., F. K. Barker, and R. S. Voss. 2014. The early diversification history of didelphid marsupials: a window into South America's "Splendid Isolation." Evolution 68:684-695.

Jaramillo, C. 2002. Response of tropical vegetation to Paleogene warming. Paleobiology 28:222-243.

Jovane, L., F. Florindo, R. Coccioni, J. Dinarès-Turell, A. Marsili, S. Monechi, A. P. Roberts, and M. Sprovieri. 2007. The middle Eocene climatic optimum event in the Contessa Highway section, Umbrian Appennines, Italy. Geological Society of America Bulletin 119:413-427.

Kalmar, A., and D. J. Currie. 2010. The completeness of the continental fossil record and its impact on patterns of diversification. Paleobiology 36:51-60.

Kelly, E. M., and K. E. Sears. 2011. Limb specialization in living marsupial and eutherian mammals: constraints on mammalian limb evolution. Journal of Mammalogy 92:1038-1049.

Kennett, J. 1977. Cenozoic evolution of Antarctic glaciation, the Circum-Antarctic Ocean, and their impact on global paleoceanography. Journal of Geophysical Research 82:3843-3860.

Kennett, J. P. 1985. Neogene paleoceanography and plankton evolution. South African Journal of Science 81:251-253. 
Kielan-Jaworowska, Z., and R. L. Cifelli. 2001. Primitive boreosphenidan mammal (?Deltatheroida) from the Early Cretaceous of Oklahoma. Acta Palaeontologica Polonica 46:377-391.

Kielan-Jaworowska, Z., and L. A. Nessov. 1990. On the metatherian nature of the Deltatheroida, a sister group of the Marsupialia. Lethaia. 23:1-10.

Kielan-Jaworowska, Z., R. L. Cifelli, and Z.-X. Luo. 2004. Mammals from the age of dinosaurs: structure, relationships, and paleobiology. Columbia University Press, New York.

Kohn, M. J., C. A. E. Stromberg, R. H. Madden, R. E. Dunn, S. Evans, A. Palacios, and A. A. Carlini. 2015. Quasi-static EoceneOligocene climate in Patagonia promotes slow faunal evolution and mid-Cenozoic global cooling. Palaeogeography, Palaeoclimatology and Palaeoecology 435:24-37.

Krause, D. W., S. Hoffmann, J. R. Wible, E. C. Kirk, J. A. Schultz, W. von Koenigswald, J. R. Groenke, J. B. Rossie, P. M. O'Connor, E. R. Seiffert, and E. R. Dumont. 2014. First cranial remains of a gondwanatherian mammal reveal remarkable mosaicism. Nature 515:512-517.

Krockenberger, A. 2006. Lactation. Pp. 108-136 in P. Armati, C. Dickman, and I. Hume, eds. Marsupials. Cambridge University Press, Cambridge.

La Roux, J. P. 2012. A review of Tertiary climate changes in southern South America and the Antarctic Peninsula. Part 2: continental conditions. Sedimentary Geology 247-248:21-38.

Lawver, L., and L. Gahagan. 2003. Evolution of Cenozoic seaways in the circum-Antarctic region. Palaeogeography, Palaeoclimatology, Palaeoecology 198:11-37.

Legendre, S. 1982. La faune de micromammiferes du gisement burdigalien de Port-la-Nouvelle (Aude); complements et indications paleoecologiques. Bulletin de la Societe geologique de France 24:383-387.

Lillegraven, J. A. 1974. Biogeographical considerations of the marsupial-placental dichotomy. Annual Review of Ecology and Systematics 5:263-283.

—. 1975. Biological considerations of the marsupial-placental dichotomy. Evolution 29:707-722.

Liow, L. H., M. Fortelius, E. Bingham, K. Lintulaakso, H. Mannila, L. Flynn, and N. S. Stenseth. 2008. Higher origination and extinction rates in larger mammals. Proceedings of the National Academy of Sciences USA 105:6097-6102.

Lisiecki, L. E., and M. E. Raymo. 2007. Plio-Pleistocene climate evolution: trends and transitions in glacial cycle dynamics. Quaternary Science Reviews 26:56-69.

Lloyd, G. T., and M. Friedman. 2013. A survey of palaeontological sampling biases in fishes based on the Phanerozoic record of Great Britain. Palaeogeography, Palaeoclimatology, Palaeoecology 372:5-17.

Longrich, N. R., J. Scriberas, and M. A. Wills. 2016. Severe extinction and rapid recovery of mammals across the CretaceousPaleogene boundary, and the effects of rarity on patterns of extinction and recovery. Journal of Evolutionary Biology 29:1495-1512.

Lowen, M. A., R. B. Irmins, J. J. W. Sertich, P. J. Currie, and S. D. Sampson. 2013. Tyrant dinosaur evolution tracks the rise and fall of Late Cretaceous oceans. PLoS ONE 8:e79420.

Luo, Z.-X., R. L. Cifelli, and Z. Kielan-Jaworowska. 2001. Dual origin of tribosphenic mammals. Nature 409:53-57.

Luo, Z.-X., Q. Ji, J. R. Wible, and C.-X. Yuan. 2003. An Early Cretaceous tribosphenic mammal and metatherian evolution. Science 302:1934-1940.

Luo, Z.-X., C.-X. Yuan, Q. J. Meng, and Q. Ji. 2011. A Jurassic eutherian mammal and divergence of marsupials and placentals. Nature 476:442-445.

Mannion, P. D., P. Upchurch, M. T. Carrano, and P. M Barrett. 2011. Testing the effect of the rock record on diversity: a multidisciplinary approach to elucidating the generic richness of sauropodomorph dinosaurs through time. Biological Reviews of the Cambridge Philosophical Society 86:157-81.

Mannion, P. D., R. B. J. Benson, M. T. Carrano, J. P. Tennant, J. Judd, and R. J. Butler. 2015. Climate constrains the evolutionary history and biodiversity of crocodylians. Nature Communications 6:1-9.

Marshall, L. G. 1980. Systematics of the South American marsupial family Caenolestidae. Fieldiana 5:1-145.

Martin, H. 1994. Australian Tertiary phytogeography. Pp. 104-142 in R. Hill, ed. History of the Australian vegetation. Cambridge University Press, Cambridge.

- 2006. Cenozoic climatic change and the development of the arid vegetation in Australia. Journal of Arid Environments 66:533-563.

McGowran, B., and R. S. Hill. 2015. Cenozoic climatic shifts in southern Australia. Transactions of the Royal Society of South Australia 139:19-37.

McGowran, B., M. Archer, P. Bock, T. A. Sarragh, H. Godthelp, S. Hageman, S. J. Hand, R. Hill, Q. Li, P. A. Maxwell, K. J. McNamara, M. Macphail, D. Mildenhall, A. D. Partridge, J. Richardson, S. Shafik, E. M. Truswell, and M. Warne. 2000. Australasian palaeobiogeography: the Palaeogene and Neogene record. Memoirs of the Association of Australasian Palaeontologists. 23:405-470.

McNab, B. 1986. Food habits, energetics and the reproduction of marsupials. Journal of Zoology 208:595-614.

- 2005. Uniformity in the basal metabolic rate of marsupials: its causes and consequences. Revista Chilena De Historia Natural 78:183-198.

- 2008. An analysis of the factors that influence the level and scaling of mammalian BMR. Comparative Biochemistry and Physiology A 151:5-28.

Mehrotra, R. 2003. Status of plant megafossils during the early Paleogene in India. In S. L. Wing, P. Gingerich, B. Schmitz, and E. Thomas, eds. Causes and consequences of globally warm climates in the early Paleogene. Geological Society of America Special Paper 369:413-423.

Meredith, R. W., J. E. Janečka, J. Gatesy, O. A. Ryder, C. A. Fisher, E. C. Teeling, A. Goodbla, E. Eizirik, T. L. Simão, T. Stadler, and D. L. Rabosky. 2011. Impacts of the Cretaceous terrestrial revolution and KPg extinction on mammal diversification. Science 334:521-524.

Miller, A. I., and M. Foote. 1996. Calibrating the Ordovician radiation of marine life: implications for Phanerozoic diversity trends. Paleobiology 22:304-309.

Molnar, P. 2008. Closing of the Central American Seaway and the Ice Age: a critical review. Paleoceanography 23:PA2201.

Montes, C., A. Cardona, C. Jaramillo, A. Pardo, J. C. Silva, V. Valencia, C. Ayala, L. C. Pérez-Angel, L. A. Rodriguez-Parra, V. Ramirez, and H. Niño. 2015. Middle Miocene closure of the Central American seaway. Science 348:226-229.

Montes, M., F. Nozal, S. Santillana, S. Marenssi, and E. Olivero. 2013. Mapa Geologico de la isla Marambio (Seymour) Escala 1:20.000 Primera Edicion. Serie Cartografica Geocientıfica Antartica. Madrid-Instituto Geologico y Minero de Espana. Instituto Antartico Argentino, Buenos Aires.

Moran, K., J. Backman, H. Brinkhuis, S. C. Clemens, T. Cronin, G. R. Dickens, F. Eynaud, J. Gattacceca, M. Jakobsson, R. W. Jordan, M. Kaminski, J. King, N. Koc, A. Krylov, N. Martinez, J. Matthiessen, D. McInroy, T. C. Moore, J. Onodera, M. O'Regan, H. Pälike, B. Rea, D. Rio, T. Sakamoto, D. C. Smith, R. Stein, K. St John, I. Suto, N. Suzuki, K. Takahashi, M. Watanabe, M. Yamamoto, J. Farrell, M. Frank, P. Kubik, W. Jokat, and Y. Kristoffersen. 2006. The Cenozoic palaeoenvironment of the Arctic Ocean. Nature 441:601-605.

Morley, R. J. 2000. The origin and evolution of tropical rain forests. Wiley, New York.

Mörner, N. A., and C. Sylwan. 1989. Magnetostratigraphy of the Patagonian moraine sequence at Lago Buenos Aires. Journal of South American Earth Sciences 2:385-389. 
Morton, S. R., H. F. Recher, S. D. Thompson, and R. W. Braithwaite. 1982. Comments on the relative advantages of marsupial and eutherian reproduction. American Naturalist 120:128-134.

Muirhead, J., L. Dawson, and M. Archer. 1997. Perameles bowensis, a new species of Perameles (Peramelemorphia, Marsupialia) from Pliocene faunas of Bow and Wellington Caves, New South Wales. Proceedings of the Linnean Society of New South Wales 117:163-174.

Nessov, L. A. 1985. Redkie kostnye ryby, nazemiye yashcheritsy i mlekopitayushchie zony limanov i primorskikh nizmennostey mela Kyzylkumov [Rare bony fishes, terrestrial lizards, and mammals in the estuarine and coastal lowland zone of the KyzylKum Cretaceous]. Yearbook of the All-Union Paleontological Association 28:199-219.

Newham, E., R. B. J. Benson, P. Upchurch, and A. Goswami. 2014. Mesozoic mammaliaform diversity: the effect of sampling corrections on reconstructions of evolutionary dynamics. Palaeogeography, Palaeoclimatology, Palaeoecology 412:32-44.

Nicholson, D. B., P. A. Holroyd, R. B. J. Benson, and P. M. Barrett. 2015. Climate-mediated diversification of turtles in the Cretaceous. Nature Communications 6:1-8.

O'Leary, M. A., J. I. Bloch, J. J. Flynn, T. J. Gaudin, A. Giallombardo, N. P. Giannini, S. L. Goldberg, B. P. Kraatz, Z.-X. Luo, J. Meng, X. Ni, M. J. Novacek, F. A. Perini, Z. S. Randall, G. W. Rougier, E. J. Sargis, M. T. Silcox, N. B. Simmons, M. Spaulding, P. M. Velazco, M. Weksler, J. R. Wible, and A. L. Cirranello. 2013. The placental mammal ancestor and the post-K-Pg radiation of placentals. Science 339:662-667.

Ortiz-Jaureguizar, E. 2003. Relaciones de similitud, paleoecología y extinción de los Abderitidae (Marsupialia, Paucituberculata). Coloquios de Paleontología, Extra Volume 1:475-498.

Ortiz-Jaureguizar, E., and G. A. Cladera. 2006. Paleoenvironmental evolution of southern South America during the Cenozoic. Journal of Arid Environments 66:498-532.

Ortiz-Jaureguizar, E., and R. Pascual. 2007. The tectonic setting of the Caribbean region: key in the radical Late Cretaceous-Early Paleocene South American land-mammal turnover. Pp. 301-307 in E. Diaz-Martinez and I. Rabano, eds. Fourth European Meeting on the Palaeontology and Stratigraphy of Latin America. Instituto Geologico y Minero de Espana, Madrid.

Owen, R. 1838. Appendix to Mitchell, T. L. Fossil remains from Wellington Valley, Australia. Marsupialia. Pp. 359-369 in Three expeditions into the interior of Eastern Australia, with descriptions of the recently explored region of Australia Felix, and of the present colony of New South Wales. T. and W, Boone, London.

Padian, K., and W. Clemens. 1985. Terrestrial vertebrate diversity: episodes and insights. Pp. 41-96 in J. W. Valentine, ed. Phanerozoic diversity patterns: profiles in macroevolution. Princeton University Press, Princeton, N.J.

Palazzesi, L., and V. Barreda. 2012. Fossil pollen records reveal a late rise of open-habitat ecosystems in Patagonia. Nature Communications 3:1294.

Palazzesi, L., V. D. Barreda, J. I. Cuitino, M. V. Guler, M. C. Telleria, and R. V. Santos. 2014. Fossil pollen records indicate that Patagonian desertification was not solely a consequence of Andean uplift. Nature Communications 5:3558.

Pascual, R., and E. Ortiz-Jaureguizar. 2007. The Gondwanan and South American episodes: two major and unrelated moments in the history of the South American mammals. Journal of Mammalian Evolution 14:75-137.

Pascual, R., E. Ortiz-Jaureguizar, and J. L. Prado. 1996. Land mammals: paradigm of Cenozoic South American geobiotic evolution. In. Contribution of Southern South America to Vertebrate Paleontology. Muncher Geowissenschaftliche Abhandlungen (A) 30:265-319.

Patterson, B., and R. Pascual. 1972. The fossil mammal fauna of South America. Pp. 247-309 in A. Keast, F. C. Erk, and B. Glass, eds. Evolution, mammals, and southern continents. State University of New York Press, Albany.

Pearson, M. R., R. B. J. Benson, P. Upchurch, J. Fröbisch, and C. F. Kammerer. 2013. Reconstructing the diversity of early terrestrial herbivorous tetrapods. Palaeogeography, Palaeoclimatology, Palaeoecology 372:42-49.

Peters, S. E., and M. Foote. 2001. Biodiversity in the Phanerozoic: a reinterpretation. Paleobiology 27:583-601.

Pledge, N. S. 1987. Phascolarctos maris, a new species of koala (Marsupialia: Phascolarctidae) from the Early Pliocene of South Australia. Pp. 327-330 in M. Archer, ed. Possums and opossums: studies in evolution. Surrey Beatty and Sons and the Royal Zoological Society of New South Wales, Sydney.

Pough, F. H., R. M. Andrews, J. E. Cadle, M. L. Crump, A. H. Savitzky, and K. D. Wells. 2004. Herpetology, 3rd ed. Benjamin Cummings, Upper Saddle River, N.J.

Prevosti, F. J., A. Forasiepi, and N. Zimicz. 2013. The evolution of the Cenozoic terrestrial mammalian predator guild in South America: competition or replacement? Journal of Mammalian Evolution 20:3-21.

Quattrocchio, M., J. Durango de Cabrera, and C. Galli. 2003. Formación Anta (Mioceno Temprano/Medio), Subgrupo Metán (Grupo Orán), en el río Piedras, Pcia. de Salta. Datos palinológicos. Revista de la Asociación Geológica Argentina 58:117-127.

R Development Core Team. 2016. R: a language and environment for statistical computing. R Foundation for Statistical Computing, Vienna, Austria. https://www.R-project.org.

Rage, J.-C. 1981. Les continents péri-atlantiques au Crétacé Supérieur: Migrations des faunes continentales et problèmes paléogéographiques. Cretaceous Research 2:65-84.

-1 1986. South American/North American terrestrial interchanges in the latest Cretaceous: short comments on Brett-Surman and Paul (1985), with additional data. Journal of Vertebrate Paleontology 6:382-383.

Rana, R. S., and G. P. Wilson. 2003. New Late Cretaceous mammals from the Intertrappean beds of Rangapur, India and paleobiogeographic framework. Acta Palaeontologica Polonica 48: 331-348.

Raup, D. M. 1972. Taxonomic diversity during the Phanerozoic. Science 177:1065-1071.

— . 1975. Taxonomic diversity estimation using rarefaction. Paleobiology 1:333-342.

- 1979. Biases in the fossil record of species and genera. Bulletin of the Carnegie Museum of Natural History 13:85-91.

Rea, D. K., J. C. Zachos, R. M. Owen, and P. D. Gingerich. 1990. Global change at the Paleocene-Eocene boundary: climatic and evolutionary consequences of tectonic events. Palaeogeography, Palaeoclimatology, Palaeoecology 79:117-28.

Reeder, D. M., K. M. Helgen, and D. E. Wilson. 2007. Global trends and biases in new mammal species discoveries. Museum of Texas Tech University Occasional Paper 269.

Riggs, E. S. 1934. A new marsupial saber-tooth from the Pliocene of Argentina and its relationships to other South American predacious marsupials. Transactions of the American Philosophical Society 24:1-32.

Rougier, G. W., J. R. Wible, and M. J. Novacek. 1998. Implications of Deltatheridium specimens for early marsupial history. Nature 396: 459-463.

Sahney, S., M. J. Benton, and P. Ferry. 2010. Links between global taxonomic diversity, ecological diversity and the expansion of vertebrates on land. Biology Letters 6:544-547.

Sánchez-Villagra, M. R. 2013. Why are there fewer marsupials than placentals? On the relevance of geography and physiology to evolutionary patterns of mammalian diversity and disparity. Journal of Mammalian Evolution 20:279-290.

Schulte, P., L. Alegret, I. Arenillas, J. A. Arz, P. J. Barton, P. R. Bown, T. J. Bralower, G. L. Christeson, P. Claeys, C. S. Cockell, and 
G. S. Collins. 2010. The Chicxulub asteroid impact and mass extinction at the Cretaceous-Paleogene boundary. Science 327:214-1218

Sears, K. E. 2004. Constraints on the morphological evolution of marsupial shoulder girdles. Evolution 58:2353-2370.

Seton, M., R. D. Müller, S. Zahirovic, C. Gaina, T. Torsvik, G. Shepard, A. Talsma, M. Gurnis, M. Turner, S. Maus, and M. Chandler. 2012. Global continental and ocean basin reconstructions since $200 \mathrm{Ma}$. Earth-Science Reviews 113:212-270.

Shackleton, N. J. 1995. New data on the evolution of Pliocene climate variability. Pp. 242-248 in E. S. Vrba, ed. Paleoclimate and evolution, with emphasis on human origins. Yale University Press, New Haven, Conn.

Shackleton, N. J., J. Backman, H. Zimmerman, D. V. Kent, M. A. Hall, D. G. Roberts, D. Schnitker, J. G. Baldauf, A. Desprairies, R. Homrighausen, P. Huddlestun, J. B. Keene, A. J. Kaltenback, K. A. O. Krumsiek, A. C. Morton, J. W. Murray, and J. Westberg-Smith. 1984. Oxygen isotope calibration of the onset of ice-rafting and history of glaciation in the North Atlantic region. Nature 307:620-623.

Shellito, C. J., and L. C. Sloan. 2006. Reconstructing a lost Eocene paradise. Part I: simulating the change in global floral distribution at the initial Eocene thermal maximum. Global and Planetary Change 50:1-17.

Signor, P. W. I., and J. H. Lipps. 1982. Sampling bias, gradual extinction patterns and catastrophes in the fossil record. Geological Society of America Special Paper 190:291-296.

Simons, E. L., and T. M. Bown. 1984. A new species of Peratherium (Didelphidae; Polyprotodonta): the first African marsupial. Journal of Mammalogy 65:539-548.

Slater, G. J. 2013. Phylogenetic evidence for a shift in the mode of mammalian body size evolution at the Cretaceous-Palaeogene boundary. Methods in Ecology and Evolution 4:734-744.

Smith, A. B., and A. J. M. McGowan. 2007. The shape of the Phanerozoic marine palaeodiversity curve: how much can be predicted from the sedimentary record of western Europe? Palaeontology 50:765-774.

Smith, A. S., and R. B. J. Benson. 2013. Marine diversity in the geological record and its relationship to surviving bedrock area, lithofacies diversity, and original marine shelf area. Geology 41:171-174

Tennant, J. P., P. D. Mannion, P. Upchurch, M. Sutton, and G. Price. 2017. Biotic and environmental dynamics across the Jurassic/ Cretaceous boundary: evidence for a protracted period of faunal and ecological turnover. Biological Reviews 92:776-814.

Travouillon, K. J., S. Legendre, M. Archer, and S. J. Hand. 2009. Palaeoecological analyses of Riversleigh's Oligo-Miocene sites: implications for Oligo-Miocene climate change in Australia. Palaeogeography, Palaeoclimatology, Palaeoecology 276:24-37.

Travouillon, K. J., Y. Gurovich, R. M. D. Beck, and J. Muirhead. 2010. An exceptionally well-preserved short-snouted bandicoot (Marsupialia; Peramelemorphia) from Riversleigh's OligoMiocene deposits, northwestern Queensland, Australia. Journal of Vertebrate Paleontology 30:1528-1546.

Trofimov, B. A., and F. S. Szalay. 1994. New Cretaceous marsupial from Mongolia and the early radiation of Metatheria. Proceedings of the National Academy of Sciences USA 91:12569-12573.

University of California Museum of Paleontology. 2016. Collections database. http:/ / www.ucmp.berkeley.edu/science/ collections.php, accessed 1 May 2016.

Uhen, M. D., and N. D. Pyenson. 2007. Diversity estimates, biases and historiographic effects: resolving cetacean diversity in the Tertiary. Palaeontologica Electronica 10:11A-22.

Uliana, M. A., and K. T. Biddle. 1988. Mesozoic-Cenozoic paleogeographic and geodynamic evolution of southern South America. Revista Brasileira de Geociencias 18:172-190.

Upchurch, P., P. D. Mannion, R. B. J. Benson, R. J. Butler, and M. T. Carrano. 2011. Geological and anthropogenic controls on the sampling of the terrestrial fossil record: a case study from the Dinosauria. Geological Society of London Special Publication 358:209-240.

U.S. Geological Survey. 2013. Home page. http://www.usgs.gov, accessed 1 May 2013.

Vermeij, G. J., and L. R. Leighton. 2003. Does global diversity mean anything? Paleobiology 29:3-7.

Villa, G., C. Fioroni, L. Pea, S. Bohaty, and D. Persico. 2008. Middle Eocene-late Oligocene climate variability: calcareous nannofossil response at Kerguelen Plateau, Site 748. Marine Micropaleontology 69:173-192.

Vullo, R., E. Gheerbrant, C. de Muizon, and D. Néraudeau. 2009. The oldest modern therian mammal from Europe and its bearing on stem marsupial paleobiogeography. Proceedings of the National Academy of Sciences USA 106:19910-19915.

Wall, P. D., L. C. Ivany, and B. H. Wilkinson. 2009. Revisiting Raup: exploring the influence of outcrop area on diversity in light of modern sample-standardization techniques. Paleobiology 35:146-167.

Whistler, D. P., and E. B. Lander. 2003. Chapter 11: New late Uintan to early Hemingfordian land mammal assemblages from the undifferentiated Sespe and Vaqueros Formations, Orange County, and from the Sespe and Equivalent marine formations in Los Angeles, Santa Barbara, and Ventura Counties, Southern California. Bulletin of the American Museum of Natural History 279:231-268

Wible, J. R., G. W. Rougier, M. J. Novacek, and R. J. Asher. 2007. Cretaceous eutherians and Laurasian origin for placental mammals near the K/T boundary. Nature 447:1003-1006.

Wilf, P. N., R. Cúneo, I. H. Escapa, D. Pol, and M. O. Woodburne. 2013. Splendid and seldom isolated: the paleobiogeography of Patagonia. Annual Review of Earth and Planetary Sciences 41:561.

Williamson, T. E., S. L. Brusatte, T. D. Carr, A. Weil, and B. R. Standhardt. 2012. The phylogeny and evolution of CretaceousPalaeogene metatherians: cladistic analysis and description of new early Palaeocene specimens from the Nacimiento Formation, New Mexico. Journal of Systematic Palaeontology 10: 625-651.

Williamson, T. E., S. L. Brusatte, and G. P. Wilson. 2014. The origin and early evolution of metatherian mammals: the Cretaceous record. ZooKeys 465:1-76.

Wilson, D. E., and D. M. Reeder. 2005. Mammal species of the world. Johns Hopkins University Press, Baltimore, Md.

Wilson, G. P. 2013. Mammals across the K/Pg boundary in northeastern Montana, U.S.A.: Dental morphology and body size patterns reveal extinction selectivity and immigrant-fueled ecospace filling. Paleobiology 39:429-469.

- 2014. Mammalian extinction, survival, and recovery dynamics across the Cretaceous-Paleogene boundary in northeastern Montana, USA. Pp. 365-392 in G. P. Wilson, W. A. Clemens, J. H. Horner, and J. H. Hartman, eds. Through the end of the Cretaceous in the type locality of the Hell Creek Formation in Montana and adjacent areas. Geological Society of America Special Paper 503.

Wilson, G. P., A. R. Evans, I. J. Corfe, P. D. Smits, M. Fortelius, and J. Jernvall. 2012. Adaptive radiation of multituberculate mammals before the extinction of dinosaurs. Nature 483:457.

Wing, S. L. 1998. Tertiary vegetation of North America as a context for mammalian evolution. In C. M. Janis, K. M. Scott, and L. L. Jacobs, eds. Evolution of Tertiary mammals of North America 1:37-65. Cambridge University Press, Cambridge.

Wing, S. L., G. J. Harrington, J. I. Bloch, D. M. Boyer, and F. Smith. 2004. Major transient floral change during the Paleocene-Eocene thermal maximum. American Geophysical Union Fall Meeting, Abstracts, PP14A-07.

Wolfe, J. A., and D. L. Dilcher. 1999. Late Paleocene through Middle Eocene Climates in Lowland North America. Pp. 184-185 in F. P. Andreasson, B. Schmitz, and E. I. Thompson, eds. 
Early Paleogene warm climate and biosphere dynamics. Earth Sciences Center, Goteborg University, Goteborg, Sweden.

Woodburne, M. O. 2004. Late Cretaceous and Cenozoic mammals of North America: biostratigraphy and geochronology. Columbia University Press, New York.

. 2010. The Great American Biotic Interchange: dispersals, tectonics, climate, sea level and holding pens. Journal of Mammalian Evolution 17:245-264.

Zachos, J., M. Pagani, L. Sloan, E. Thomas, and K. Billups. 2001. Trends, rhythms, and aberrations in global climate $65 \mathrm{Ma}$ to present. Science 292:686-693.
Zhang, P. Z., P. Molnar, and W. R. Downs. 2001. Increased sedimentation rates and grain sizes 2-4 Myr ago due to the influence of climate change on erosion rates. Nature 410 : 891-897.

Ziegler, R. 1990. Didelphidae, Erinaceidae, Metacodontidae und Dimylidae (Mammalia) aus dem Oberoligozän und Untermiozän Süddeutschlands. Stuttgarter Beiträge zur Naturkunde, Serie B 158:1-99.

Zimicz, N. 2014. Avoiding competition: the ecological history of late Cenozoic metatherian carnivores in South America. Journal of Mammalian Evolution 21:383-393. 